OPEN ACCESS

Edited by:

Harold Cremer,

Centre National de la Recherche

Scientifique (CNRS), France

Reviewed by:

Ryuji Morizane,

Brigham and Women's Hospital and

Harvard Medical School,

United States

David Pamies,

Université de Lausanne, Switzerland

*Correspondence:

Sofia B. Lizarraga

lizarras@mailbox.sc.edu

${ }^{t}$ These authors have contributed

equally to this work

Specialty section:

This article was submitted to

Neurogenesis,

a section of the journal

Frontiers in Neuroscience

Received: 28 January 2019

Accepted: 22 May 2019

Published: 21 June 2019

Citation:

Chukwurah E, Osmundsen A, Davis SW and Lizarraga SB (2019) All

Together Now: Modeling

the Interaction of Neural With

Non-neural Systems Using Organoid

Models. Front. Neurosci. 13:582.

doi: 10.3389/fnins.2019.00582

\section{All Together Now: Modeling the Interaction of Neural With Non-neural Systems Using Organoid Models}

\author{
Evelyn Chukwurah ${ }^{1,2 t}$, Allison Osmundsen ${ }^{1,2 t}$, Shannon W. Davis ${ }^{1,2}$ and \\ Sofia B. Lizarraga ${ }^{1,2 *}$ \\ ${ }^{1}$ Department of Biological Sciences, University of South Carolina, Columbia, SC, United States, ${ }^{2}$ Center for Childhood \\ Neurotherapeutics, University of South Carolina, Columbia, SC, United States
}

The complex development of the human nervous system has been traditionally studied using a combination of animal models, human post-mortem brain tissue, and human genetics studies. However, there has been a lack of experimental human cellular models that would allow for a more precise elucidation of the intricate dynamics of early human brain development. The development of stem cell technologies, both embryonic and induced pluripotent stem cells (iPSCs), has given neuroscientists access to the previously inaccessible early stages of human brain development. In particular, the recent development of three-dimensional culturing methodologies provides a platform to study the differentiation of stem cells in both normal development and disease states in a more in vivo like context. Three-dimensional neural models or cerebral organoids possess an innate advantage over two-dimensional neural cultures as they can recapitulate tissue organization and cell type diversity that resemble the developing brain. Brain organoids also provide the exciting opportunity to model the integration of different brain regions in vitro. Furthermore, recent advances in the differentiation of non-neuronal tissue from stem cells provides the opportunity to study the interaction between the developing nervous system and other non-neuronal systems that impact neuronal function. In this review, we discuss the potential and limitations of the organoid system to study in vitro neurological diseases that arise in the neuroendocrine and the enteric nervous system or from interactions with the immune system.

Keywords: pluripotent, organoids, Alzheimer's, microglia, neuroimmune, neuroendocrine, gut, Zika

\section{INTRODUCTION}

The formation of the complex nervous system is a fascinating and crucial series of events that occurs during human development. From the formation of the neural plate in the third week of gestation to the migration of neural crest cells throughout the periphery of the embryo, the nascent nervous system undergoes a series of dramatic changes that produce an intricate network of neural cells that make up the central and peripheral nervous systems (CNS and PNS). This is achieved by the careful coordination of multiple cellular events that include: neuronal progenitor cell (NPC) proliferation, neuronal or glial cell differentiation, neuronal morphogenesis, maturation, and migration. After 
the formation of the different brain regions, neurons establish connections with specific target cells that are critical to their pre-determined functions.

Most of our current understanding of the intricacies of human nervous system development have come from human genetic studies (Bae et al., 2015), post-mortem tissue analysis (Kretzschmar, 2009; Jhou and Tai, 2017), and work in multiple animal models. Vertebrate and invertebrate animal model systems have given remarkable insight into the genetic programs responsible for the patterning and regionalization of the nervous system that results in different brain structures (Hebert and Fishell, 2008; Doe, 2017). In particular, elegant genetic approaches in murine models have allowed for the systemic or brain region-specific miss-expression of neural genes, leading to the experimental characterization of neural development, and function (Del Pino Rico and Marin, 2018). However, significant differences exist between the murine and human nervous systems, including varying degrees of circuit complexity, and brain architecture (DeFelipe, 2015). For instance, the lack of gyri and reduced number of outer radial glial cells (oRGCs), a specialized type of neuronal progenitors, in the murine brain compared to the primate brain diminishes the faithful recapitulation of human neurodevelopmental disorders in rodents (Shitamukai et al., 2011; Sun and Hevner, 2014). This highlights the need to establish easily malleable human model systems. This niche was filled in part by the establishment of neuroblastoma cell lines that were amenable to neuronal differentiation and genetic manipulations. Subsequently the establishment of neurosphere cultures from post-mortem fetal brain contributed to the study of neurodevelopmental disorders, such as brain malformations (Sheen et al., 2006; Lu et al., 2011) and Down syndrome (Bahn et al., 2002). Recently, the use of post-mortem human fetal neocortex tissue in combination with single cell transcriptomics (Pollen et al., 2014, 2015; Liu et al., 2016; Nowakowski et al., 2017, 2018) and epigenetic approaches (Yoon et al., 2017a) uncovered temporal and spatial gene programs governing fetal brain development. However, small sample sizes, discreet temporal windows in development, the inability to conduct genetic manipulations, and ethical implications associated with the source of the tissue limit this model system (Farahany et al., 2018). Therefore, the development of human stem cell technology, especially three-dimensional (3D) cultures, constitutes an unparalleled opportunity to study the early stages of human neuronal development in an otherwise inaccessible tissue. These 3D cultures are becoming more complex and have many advantages, such as investigating the interactions between diverse cell types and tissues (Figure 1), but also have limitations, such as the inability to develop a vasculature system, which remain as challenges in the organoid field as it develops (For a summary of advantages and limitations of organoid systems see Table 1; Antoni et al., 2015).

The seminal work by Gurdon (Gurdon et al., 1958; Gurdon, 1960 ) and the group of Shinya Yamanaka (Takahashi and Yamanaka, 2006; Takahashi et al., 2007) to revert an adult somatic cell to an embryonic state by nuclear reprogramming set the stage for the massive expansion in the use of human induced pluripotent stem cell (iPSC) derived models. Stem cell technology, combined with information on brain patterning signaling pathways, allowed for the development of protocols to induce neuronal (Marchetto et al., 2008; Shi et al., 2012b; Maroof et al., 2013; Kim et al., 2014; Yu et al., 2014; Ahn et al., 2016), and glial cell types (Hu et al., 2009; Shaltouki et al., 2013; Muffat et al., 2016b; Santos et al., 2017) in two-dimensional (2D) in vitro cultures. 2D stem cell derived neural models provide a human platform to conduct molecular, cellular, or physiological studies and are amenable to high throughput drug screening (Darville et al., 2016; Rana et al., 2017; Wang C. et al., 2017). These models are uncovering the cellular and molecular mechanisms underlying the pathology of neurological disorders for which animal models fall short, such as Alzheimer's disease (AD) (Israel et al., 2012; Muratore et al., 2014, 2017; Moore et al., 2015), and schizophrenia (Hook et al., 2014; Hoffman et al., 2017). However, a major limitation of 2D models is that they cannot recapitulate the in vivo 3D spatial organization present in the nervous system that results from the interactions of different neural cell types. For example, 2D models can replicate the temporal sequence of events necessary for corticogenesis in the cerebral cortex, but cannot generate its architectural organization, which is critical for understanding the neural networks necessary for normal function and that are disrupted in disease states. Thus, the development of 3D stem cell derived neural model systems has revolutionized how we study the development of the cerebral cortex (Quadrato and Arlotta, 2017; Pasca, 2018b). 3D neural models or brain organoids resemble the multicellular and three-dimensional nature of the structures present in the CNS and can replicate the early stages of brain development (Lancaster et al., 2013; Lancaster and Knoblich, 2014a; Quadrato et al., 2017; Renner et al., 2017). Stem cells grown as embryod bodies embedded in Matrigel, an extracellular matrix material, have been used as the starting material in brain organoid cultures. In the absence of exogenous patterning signals the formation of cerebral organoids composed of multiple brain regions was observed (Lancaster et al., 2013; Quadrato et al., 2017). Recently, by manipulating multiple signaling pathways in these culture systems, researchers have now been able to drive the production of different region-specific brain structures in vitro (Jo et al., 2016; Marton and Pasca, 2016; Qian et al., 2016; Birey et al., 2017).

In vivo, the generation of neurons from neural stem cells occurs prior to the formation of glial cells. This temporal sequence of neurogenesis and gliogenesis is conserved in 3D culturing systems, as astrocytes were shown to appear much later in culture (Renner et al., 2017). Initially, oligodendrocytes the myelinating cells in the brain, were not observed in self-directed cerebral organoids; however, recent work using a 3D model based on the aggregation of NPCs, showed that after 8 weeks in culture there was evidence of myelination (Pamies et al., 2017). Similarly, the generation of organoids that contain oligodendrocytes, as well as neurons and astrocytes was recently reported (Marton et al., 2019). Furthermore, brain-region organoids lacked microglia, the immune cells in the brain, which come from a non-ectodermal cell lineage. However, protocols that allow for the differentiation of both mesodermal and neural progenitors from iPSC within 


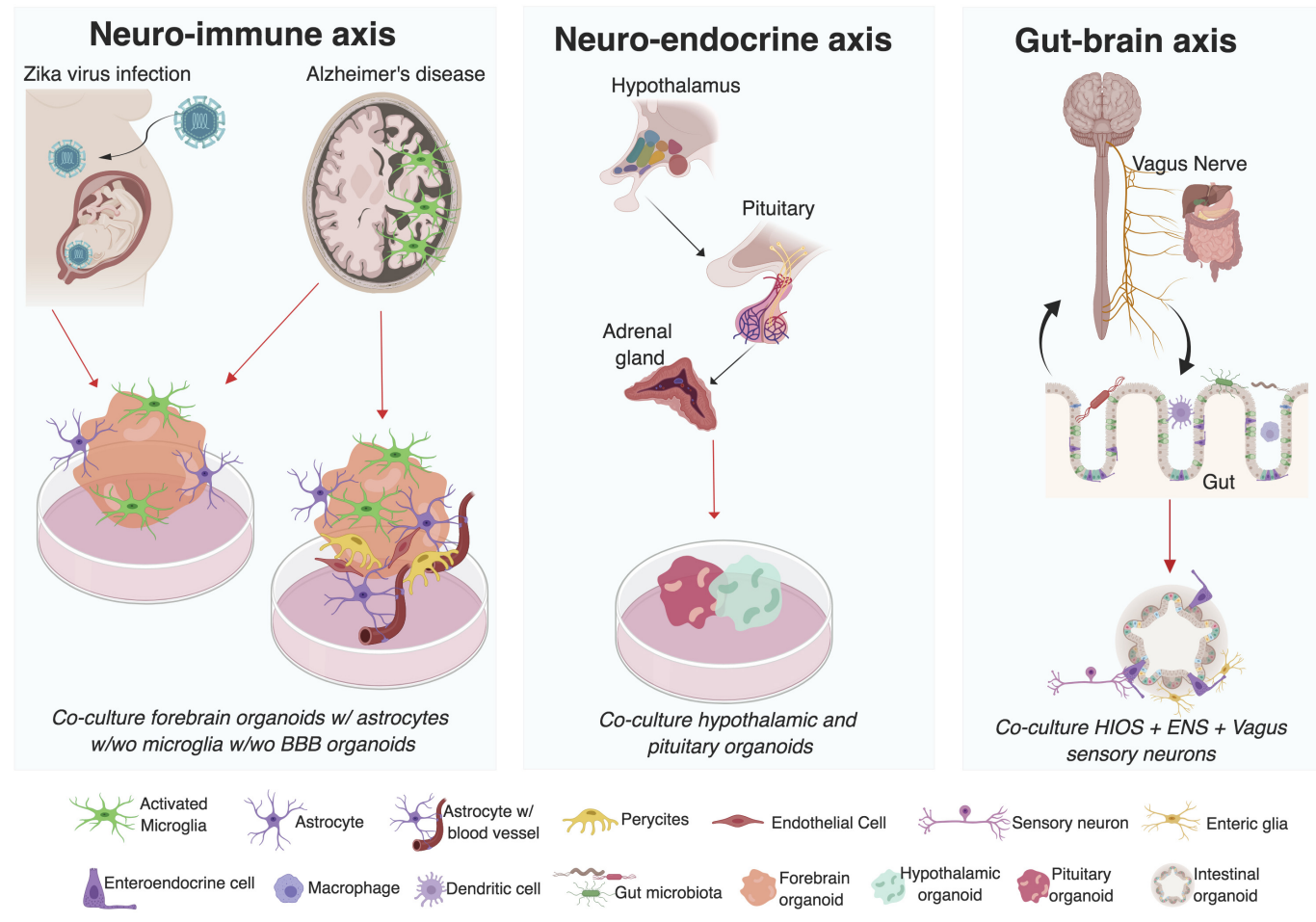

FIGURE 1 | Investigating interactions between multiple systems using organoid co-culture systems. Mechanisms underlying the neuro-immune, neuro-endocrine, and gut-brain axis in humans can be investigated utilizing organoid co-culture systems. Advances have already been made in the use of brain region specific organoids co-cultured with microglia (resident immune cells in the brain) in the study of ZIKV induced microcephaly and Alzheimer's disease. Similarly, advances in the development of blood brain barrier (BBB) stem cell models highlights the exciting possibility of investigating the role of the BBB thinning in AD pathogenesis. Enteric organoids that combine intestinal ( $\mathrm{HIOS}$ ) and enteric nervous system (ENS) cellular components and vagal sensory neurons suggest the possibility to interrogate the mechanisms underlying the gut-brain interactions in vitro. Finally, the development of different organoid models of human pituitary and hypothalamic tissue has also been reported. Even though to date there is no organoid model of the adrenal gland, this could potentially be used to interrogate different components of the neuro-endocrine axis. (Figure was created with BioRender.com softwared. Abbreviations used w/wo is with or without).

TABLE 1 | Advantages and disadvantages of organoid systems.

\section{Advantages}

Access to previously inaccessible tissue that would have only been available post-mortem

Contain same genetic background as patients in case of iPSC-derived organoids

In instances where iPSCs are unavailable, researchers can use genome editing to introduce disease-associated mutations in stem cells to derive organoids

Preponderance of protocols to derive various organoids that can be scaled up or down depending on laboratory capabilities

Provides a more "in vivo" like human cellular model for drug screening

3D microenvironment that more faithfully recapitulates cell-cell interactions than 2D models

\section{Disadvantages}

Wide variability has been noted in brain organoids cultured under identical conditions

No standardized protocol for establishing organoid models - Which protocol is the right protocol?

Difficulty in modeling interacting systems requiring organoids to be cultured under different conditions. Trans-well culture systems developed, but prevent direct physical interaction, which may be required

No established methodology to introduce functional vascularization into brain organoids, short of engrafting the organoids into rodent hosts

Cultures are more representative of fetal developmental stages rather than postnatal stages

Clonal variability, even among iPSCs from the same patient, requires the use of multiple clones to generate organoids the same organoid, showed the spontaneous development of phagocytic microglia (Ormel et al., 2018). Another option for generating organoids that mimic in vivo conditions of brain development is to establish co-culture conditions that recapitulate the interactions between glial and neuronal cells (Krencik et al., 2017; Sloan et al., 2017; Cvetkovic et al., 2018). For example, organoids that incorporated human microglia were also developed by co-culturing an SV40 human microglia cell line with brain organoids (Abreu et al., 2018). Taken together these different strategies to integrate neural and glial lineages are highly relevant to modeling brain development in a dish, because glial cells are relevant to the formation, and function of neuronal circuitry (Wu et al., 2015; Allen and Lyons, 2018). Organoids 
have also been employed in the study of the tissue-specific conditions of neuronal and glial function in the PNS as seen in enteric nervous system (McCracken et al., 2011; Fattahi et al., 2016).

Within the context of neurological disease, organoids from patient-derived iPSCs have provided an additional platform to identify key cellular and molecular hallmarks underlying disease pathogenesis (Mariani et al., 2015; Qian et al., 2016; Raja et al., 2016; Bershteyn et al., 2017; Li et al., 2017; Seo et al., 2017). For example Lancaster et al. (2013) reported the first patient derived cerebral organoid model of human microcephaly associated with mutations in the centrosomal gene CDK5RAP2. Similarly, cerebral organoids of Miller-Dieker syndrome patients with a severe form of lissencephaly, showed mitotic defects in oRGCs, which is a critical progenitor for cortical expansion in humans (Bershteyn et al., 2017). Finally, neural organoids derived from patients with idiopathic autism had increased production of inhibitory neurons compared to unaffected controls (Mariani et al., 2015). Therefore, in less than a decade that this technology has been developed it has been key in the study of neurodevelopmental and neuropsychiatric disorders. In the absence of patientderived iPSCs, CRISPR-mediated gene editing techniques have allowed researchers to introduce disease-associated mutations into stem cells and in so doing, closely capture the neurological disease state (Wang P. et al., 2017) and further highlight the power of the stem cell technology to study human disease.

The proliferation of $3 \mathrm{D}$ stem cell derived models provides an expanding scientific playground in which we can begin to ask key questions in human biology using a multi-system approach. During development and in disease, there can be a mutual dependence of the nervous system on other non-neural systems for proper function. A key example is the relationship between the cardiovascular and the nervous system. During embryogenesis the development of the vasculature has been shown to be essential for brain development and function (Paredes et al., 2018). The relevance of the interaction between neuronal and non-neuronal systems is also highlighted by the autonomic and somatic motor systems of the PNS. In these systems, the nervous system regulates the function of non-neuronal tissue by sending and receiving information that could elicit the contraction of skeletal muscle tissue, for example. This prompts the following questions: How well can organoid models recapitulate multi-system interactions? And, can neural circuits that span multiple systems be replicated in vitro? Previous reviews on cerebral organoids have focused on the principles of organogenesis and tissue morphogenesis (Lancaster and Knoblich, 2014b; Jabaudon and Lancaster, 2018; Pasca, 2018a), methodologies (Kelava and Lancaster, 2016), integration of different brain regions (Birey et al., 2017; Pasca, 2018a), and the study of development or disease (Muffat et al., 2016a; Quadrato et al., 2016; Amin and Pasca, 2018; Brown et al., 2018; Heide et al., 2018; Pasca, 2018b). Here, we focus on the potential of organoids to model interactions between the nervous system with non-neural systems (Figure 1). We further discuss how alterations in these systems contribute to our understanding of human neuronal development and disease.

\section{ORGANOID MODELING OF NEURO-IMMUNE AND NEURO-VASCULAR INTERACTIONS}

Early experiments with dye injections into guinea pig (Wislocki, 1891) and pig embryos (Weed, 1917) showed an astonishing absence of staining in the embryonic brain and spinal cord, suggesting that the CNS was compartmentalized away from the rest of the circulating blood and lymph. Subsequent transplantation of rat sarcoma tissue into mouse skin, muscle, and brain parenchyma showed that shortly after transplantations only the rat tissue transplanted into the CNS was protected from immunological attack (Shirai, 1921). These results suggested that the brain and spinal cord are in a state of immunological privilege and are devoid of infectious pathogens present in blood and lymph due to the presence of a blood-brain-barrier (BBB). The $\mathrm{BBB}$ is a specialized endothelial cell membrane (Reese and Karnovsky, 1967; Brightman and Reese, 1969) that controls the traffic from the blood into the vascular space of the brain (Banks, 2015). During normal physiological conditions the $\mathrm{BBB}$ tightly restricts the passage of immune-reactive molecules and immune cells from the systemic circulation into the CNS (Banks et al., 2012), while allowing passive gaseous exchange and carrier or receptor-mediated transport of select molecules.

A growing body of work suggests that thinning of the $\mathrm{BBB}$ allows immune response cells from the circulating periphery to infiltrate the CNS, and in turn induce the chronic neuro-inflammation associated with AD (Regen et al., 2017; Zenaro et al., 2017). These inflammatory conditions are also driven by the activation of the microglia (Regen et al., 2017). Microglia are responsible for the surveillance of the immune landscape in the CNS, arise from hematopoietic precursors that migrate to the neuroepithelium prior to the closure of the neural tube, and differentiate to become the resident CNS phagocytic immune cells (Alliot et al., 1999; Ginhoux et al., 2010; Swinnen et al., 2013). As such, microglia can respond quickly to the presence of pathogens that breach the BBB by exerting phagocytosis (Nicolas-Avila et al., 2018) and acting as traditional antigen presenting cells (Mack et al., 2003). Microglia play key roles in the wiring of the brain by regulating synapse pruning and maturation (Tremblay et al., 2010; Paolicelli et al., 2011; Schafer et al., 2012; Bialas and Stevens, 2013), as well as maintaining brain health by clearing dying or stressed neurons from the CNS (Davalos et al., 2005).

The relevance of neuro-immune interactions in brain health is further highlighted by studies on maternal immune activation in the etiology of neuropsychiatric disorders like autism and schizophrenia (Estes and McAllister, 2016; Nardone and Elliott, 2016; Careaga et al., 2017). In this section, we discuss the use of organoids to model the complex interactions that occur between neurons and glial cells in the neuro-immune axis, especially in the context of Zika virus $(Z I K V)$ infections and $\mathrm{AD}$ 
pathogenesis. We also discuss models of the $\mathrm{BBB}$ and its role in mediating neuro-immune responses and potentially modeling the neuro-vascular axis.

\section{Modeling Neuro-Immune Interaction in ZIKV Microcephalic Organoids}

The cerebral cortex begins as a single neuroepithelial sheet that borders CSF-filled lateral ventricles. Neuroepithelial progenitor cells are aligned along a basal-apical axis and give rise to specialized proliferative regions. In higher mammals, the developing cerebral cortex contains three proliferative regions: the ventricular zone (VZ), the subventricular zone (SVZ), and the outer subventricular zone (OSVZ) (Lehtinen and Walsh, 2011; Lui et al., 2011). Remarkably this in vivo organization of the cerebral cortex is closely mirrored in self-directed and forebrain patterned organoids (Lancaster et al., 2013; Quadrato et al., 2017; Qian et al., 2018), which develop a primitive cortical plate structure and contain neurogenic regions equivalent to those found in vivo (VZ, SVZ, and OSVZ). These results suggest that the neurogenic and migratory pathways associated with in vivo cortical development are also replicated in vitro (Lancaster et al., 2013; Renner et al., 2017; Qian et al., 2018).

By resembling the early fetal brain stages, cerebral organoid technology provides an ideal model to study the early stages of human neuronal development and has been instrumental in the study of ZIKV infection of the fetal brain (Song et al., 2017). Expectant mothers who contracted the flavivirus $Z I K V$ through the bites of $Z I K V$-infected mosquitoes gave birth to children with pronounced microcephaly (small brain), showing a primarily reduced cerebral cortex (Kikuti et al., 2018). Postmortem studies and 2D neuronal models indicated that NPCs are the primary affected cell types (Mlakar et al., 2016; Tang et al., 2016; Strafela et al., 2017). Several groups have now utilized organoid technology to model infection by ZIKV during fetal brain development (Qian et al., 2016; Salick et al., 2017) and to elucidate the molecular underpinnings of $Z I K V$ entry into its neural host cell types (Garcez et al., 2016; Wells et al., 2016; Yoon et al., 2017b). These studies showed that ZIKV microcephaly correlates with a decrease in the size of the $\mathrm{VZ}$ due to reduced NPC proliferation and increased apoptosis of NPCs (reviewed in Qian et al., 2017; Chen et al., 2019; Setia and Muotri, 2019). Using customized mini-bioreactors and forebrain organoids, Qian et al. (2016) demonstrated that ZIKV infection has the most pronounced effect during the first trimester of fetal development, when the developing cortex is predominantly populated by NPCs that will proliferate and differentiate to form the majority of the cerebral cortex.

While the most severe effect of $Z I K V$ was seen in NPCs, a remaining question was whether $Z I K V$ could utilize glial cells to initiate or perpetuate NPC infection in the developing brain. Muffat et al. (2018) found that while ZIKV was able to replicate inside of iPSC-derived astrocytes and microglia, it did not increase cell death in these cell types. Thus, ZIKV infected glial cells could serve as putative viral reservoirs within the brain. In particular, ZIKV infected microglia could act as Trojan horses to breach the immunological privilege of the brain by bringing in infectious viral loads during their early migration into the neural tube. In fact, NPCs were efficiently infected with supernatant of $Z I K V$-infected microglia (Muffat et al., 2018). Similarly, co-cultures of $Z I K V$-infected microglia with neuralized forebrain cortical organoids showed that microglia migrated into the organoid tissue, matured, and infected organoid NPCs with $Z I K V$, leading to a microcephalic-like phenotype in the organoids (Muffat et al., 2018). Therefore, the infective potential of $Z I K V$ in the developing brain might be further amplified by the presence of microglial viral reservoirs. These findings highlight the usefulness of co-culture systems in the study of how different cell types might contribute to the disease phenotype.

$Z I K V$ induced microcephaly is an extreme example of how a maternal transmitted infection can have detrimental consequences during fetal brain development. However, it is not the only example, as several studies have shown that inflammation during pregnancy increases the risk for neuropsychiatric disorders, such as autism and schizophrenia (Estes and McAllister, 2016; Careaga et al., 2017). Similarly, the impact of inflammation in the adult brain and neurodegenerative disorders is a growing field of research. Next, we discuss the use of organoids to model the impact of the neuro-immune axis in neurodegeneration.

\section{Neuroimmune Interactions in the Adult Brain: AD Organoid Models}

Alzheimer's disease affects close to $7 \%$ of adults around the world and is characterized by progressive cognitive decline that leads to age-related dementia. The major hallmarks of $\mathrm{AD}$ pathology are the accumulation of amyloid- $\beta(\mathrm{A} \beta)$ plaques within extracellular spaces and neurofibrillary tangles, formed by deposition of hyperphosphorylated TAU within neurons. The $\mathrm{A} \beta$ hypothesis of $\mathrm{AD}$ pathology posits that the accumulation of $A \beta$ plaques leads to neurofibrillary tangles and induces a state of chronic neuroinflammation, which in turn worsens $\mathrm{AD}$ pathology (McGeer and McGeer, 2013). In AD, the $\beta$ - and $\gamma$-secretases cleave Amyloid Precursor Protein (APP) to produce larger amounts of a 42 amino-acid long $A \beta$ isoform - $A \beta_{42}$, which is highly prone to aggregating and accumulating in the extracellular space (Dawkins and Small, 2014). The $\mathrm{A} \beta_{42}$ aggregates are not efficiently cleared by microglia. However, the microglia do release pro-inflammatory cytokines, which induces a state of neuroinflammation that exacerbates the AD symptoms (Castillo et al., 2017). Furthermore, chronic activation of microglia and increased inflammation has been suggested to exacerbate the activation of kinases that phosphorylate TAU (Asai et al., 2015; Sanchez-Mejias et al., 2016). Hyperphosphorylation of TAU increases microtubule instability, disrupting intracellular trafficking along the microtubules, and contributes to axonal degeneration associated with $\mathrm{AD}$.

Two-dimensional stem cell derived models have been used in studies of familial $\mathrm{AD}$, in which the onset of the disease is linked to mutations in one of three genes: APP, which leads to increased APP production, or Presenilin 1 and 2 (PSEN1 and PSEN2), which results in diminished APP processing (Israel et al., 2012; Shi et al., 2012a; Muratore et al., 2014). These studies showed 
that $\mathrm{AD}$ patient-derived neurons had increased pathogenic $\mathrm{A} \beta$ peptide production and increased TAU phosphorylation (Israel et al., 2012; Muratore et al., 2014; Saurat et al., 2016) that depended on the length of time in culture (over 100 days in culture) (Muratore et al., 2014; Saurat et al., 2016). However, these cultures did not recapitulate the accumulation of amyloid plaques or intracellular neurofibrillary tangles that are hallmarks of AD. Subsequent attempts to generate a suitable microenvironment in which secreted $A \beta$ peptide could lead to the formation of amyloid plaques and intracellular neurofibrillary tangles were made using a 3D stem cell derived neural model overexpressing $\mathrm{AD}$ associated mutations in APP and PSEN1 (Choi et al., 2014). Similarly, AD cellular phenotypes were observed in PSEN1 patient derived self-organizing cerebral organoids cultured for over a 100 days in a spinning bioreactor (Lancaster et al., 2013; Kim et al., 2015; Gonzalez et al., 2018), as well as in iPSC-derived neural organoids with APP duplications ( $A P P P^{D P} 1-1$ and $A P P$ $D P P_{2-3)}$ and PSEN1 mutation (PSEN1 $1^{A 264 E}$ ) (Raja et al., 2016). However, these models did not address the role of inflammation in the progression of $\mathrm{AD}$, as these organoids did not account for the role of astrocytes or microglia in their observed phenotypes. The fact that postmortem studies showed increased microglia and activated astrocytes surrounding $\mathrm{A} \beta$ plaques in $\mathrm{AD}$ patients compared to control samples (Vehmas et al., 2003), emphasizes the importance of incorporating microglia and astrocytes into brain organoid models of AD.

Forebrain organoid models that are fated to a neuroectodermal fate produce multiple neuronal cell types, but require long-term cultures to generate astrocytes, and usually do not produce microglia, which is of mesodermal origin (Pasca et al., 2015; Sloan et al., 2017). Alternatively, self-directed organoid models generated in the absence of patterning molecules showed the presence of mesodermal lineage progenitors leading to the spontaneous development of phagocytic microglia (Ormel et al., 2018). Thus, self-directed organoids could be used to investigate the role of microglia in neurological disorders and neurodevelopment. Furthermore, the development of protocols to robustly generate microglia from human stem cells makes it possible to assess the role of microglia in $\mathrm{AD}$ pathogenesis. This system was used to investigate the pathogenicity of Apolipoprotein E (APOE) protein alleles in AD. APOE is a cholesterol transporter that has been shown to be associated with elevated risk for developing sporadic $\mathrm{AD}$ (Lopez et al., 2014). APOE is primarily expressed by astrocytes and to a lesser extent by microglia and neurons, and was found to colocalize with neurofibrillary tangles and $\mathrm{A} \beta$ plaques in postmortem $\mathrm{AD}$ tissue, demonstrating a possible connection to AD pathogenesis (Namba et al., 1991). In humans, the $A P O E$ gene has three polymorphic alleles: APOE2, APOE3, and $A P O E 4$, each with different binding affinities for $A \beta$ plaques (Hashimoto et al., 2012). Analysis of post-mortem brain tissue from $\mathrm{AD}$-afflicted individuals showed a strong correlation between the presence of APOE4 allele and the severity of $\mathrm{AD}$ hallmark pathologies. Similarly, embryonic stem cell derived neurons carrying the APOE4 allele showed higher production of $\mathrm{A} \beta$ peptide compared to the more common allele APOE3 (Huang et al., 2017). CRISPR/CAS9 genome editing was used to investigate $A P O E 4$ cell specific $\mathrm{AD}$ pathogenesis in isogenic iPSC lines were the APOE4 allele was introduced into a non-AD patient APOE3 iPSC lines (Lin et al., 2018). To determine the impact of microglia in $\mathrm{AD}$ pathology iPSC-derived APOE3 or APOE4 microglia were co-cultured with APP Dpp (APP duplication) forebrain cortical organoids. APOE4 did not affect the migration or incorporation of microglia into forebrain organoids. However, it induced morphological changes in the organoid neurons, such as elongated processes with increased $\mathrm{A} \beta$ fragments. These results suggest that APOE4 microglia might be defective in clearing the $\mathrm{A} \beta$ peptides (Lin et al., 2018).

While the role of microglia in $\mathrm{AD}$ is becoming well established, the role of astrocytes in $\mathrm{AD}$ pathogenesis remains poorly understood. Astrocytes produce their own inflammatory molecules in response to cytokines and may contribute to the pro-inflammatory response in the CNS of familial or sporadic AD patients (Rothhammer and Quintana, 2015). Already analysis of iPSC-derived APOE4 astrocytes showed reduced clearance activity of $\mathrm{A} \beta$ peptides compared to isogenic control astrocytes (Lin et al., 2018). However, the additive effect of AD mediated inflammation on astrocytes could not be tested in this $2 \mathrm{D}$ neural model. The development of long-term cerebral organoid cultures that generate astrocytes (Sloan et al., 2017) will provide an elegant model in which to assess the contribution of astrocytes to familial or sporadic AD. In summary, 3D neural models that integrate neuronal and glial cells are allowing us to investigate additional compounding factors that exacerbate $\mathrm{AD}$ pathogenesis, like inflammation.

\section{Perspectives on Modeling the BBB: Implications on the Neuro-Immune and Neuro-Vascular Axes}

In the $3 \mathrm{D}$ models of $\mathrm{AD}$ and $Z I K V$ infection discussed thus far, the role of the $\mathrm{BBB}$ in establishing the pathological conditions was not examined. With respect to $\mathrm{AD}$, a major remaining question is how do activated circulating immune cells breach the BBB to stimulate astrocytic and microglial activation and promote inflammatory conditions conductive to disease progression? With respect to $Z I K V$ induced microcephaly, a major remaining question is what cell types in the $\mathrm{BBB}$ are susceptible to $Z I K V$ viral infection, and what receptors are expressed in these cells that ease viral entry into ZIKV-target cells in the CNS? The development of stem cell derived BBB multicellular models will present a major step forward in unraveling human specific phenotypes associated not only with the impact of disease in the BBB (Lippmann et al., 2014; Lauschke et al., 2017; Campisi et al., 2018), but will also further our current understanding on how the neurovasculature contributes to neuronal development.

Different BBB models have been reported that contain cell types that constitute the $\mathrm{BBB}$ and recapitulate in part the function of the BBB. Two models using human primary astrocytes, vascular pericytes, and brain microvascular endothelial cells or immortalized cerebral endothelial cells have been described (Cho et al., 2017; Bergmann et al., 2018). In addition, a cortical spheroid model with a functional $\mathrm{BBB}$ was generated utilizing a hanging drop method that mixed in six cell types present 
in the BBB (endothelial cells, pericytes, astrocytes, microglia, oligodendrocytes, and neurons) (Nzou et al., 2018). Although this model did not survive long in culture, it did show the formation of spheroids that were selectively permeable to various compounds. While this spheroid model is not a proper brain organoid it highlights the potential of future co-cultures that incorporate brain organoids with microglia, astrocytes, and BBB organoids. In fact, recent work from Song et al. (2019) demonstrated that the fusion of cortical neuronal progenitor spheroids with endothelial spheroids and mesenchymal stem cells lead to the formation of a hybrid neurovascular organoid that develops a structure akin to a rudimentary BBB that expressed markers for tight junctions, like ZO1, which are hallmarks of endothelial barrier tissue. While these models allow us to study the role of the neurovasculature in development and disease they are still at their infancy and further research is needed to identify the specific cell types within the BBB necessary for viral entry and the cognate receptors necessary for proinflammatory cytokine entry into the developing fetal CNS. These experiments can be facilitated using organoids developed from receptor-depleted iPSC-derived BBB cells (Lippmann et al., 2013). Finally, while a major challenge to the brain organoid models has been the inclusion of vasculature, strategies creating these hybrid neurovascular organoids could potentially surpass this challenge. In addition, the incorporation of bioengineering technology into brain organoid research, as has been done on kidney organoids that were cultured under flow on millifluidic chips and resulted in the generation of a vascular network with lumens, could potentially contribute to more "in vivo" like neurovascular organoid models (Homan et al., 2019).

\section{GUT FEELING: MODELING THE ENTERIC NERVOUS SYSTEM IN 3D}

There is extensive cross talk between the PNS and the immune system, as evidenced by the extensive innervation of lymphoid organs by sympathetic post-ganglionic nerves as well as by the vagus nerve (Felten, 1993; Zila et al., 2017). Furthermore, several immune response cells release neuropeptides in response to infection and express receptors for various neurotransmitters (Felten et al., 1993). Activation of receptors by neurotransmitters stimulates the proliferation and maturation of the immune response cells promoting a timely response to pathogenic presence in the PNS (Pinho-Ribeiro et al., 2017). This could highlight a potential connection between inflammation and gastrointestinal impairments observed in neurodegenerative and neuropsychiatric disorders. In addition to AD, Parkinson's disease has a clear presentation of gastrointestinal (GI) impairments (Su et al., 2017). Similarly, GI problems are also associated with autism (Dalton et al., 2014) and have been reported in syndromic autism such as Christianson syndrome patients (Pescosolido et al., 2014). However, the extent to which GI impairments contribute to neurological pathologies in each of these disorders is not well understood. In this respect an emerging field is the study of how the gut microbiome might impact neurodevelopmental and neuropsychiatric diseases. This topic has been extensively reviewed (Fung et al., 2017; BruceKeller et al., 2018) and is not revised here. Instead, we focus on $3 \mathrm{D}$ models that integrate the enteric nervous system (ENS) or the "brain in the gut" and GI tissue. The ENS is the largest sensory organ in the body and is formed by a network of neural cells resident in the GI tract.

\section{The Complex Development and Function of the ENS}

Upon closure of the neural tube, neural crest cells migrate into the primitive gut to form the future ENS. The ENS is part of the autonomic nervous system and modulates peristaltic reflexes, fluid secretion into the lumen of the GI tract, and vasodilation of GI tract blood vessels (Kiba, 2006). The ENS is an extensive network of neurons that innervate the entire GI tract and works in conjunction with non-neuronal enteroendocrine cells and interstitial cells of Cajal (ICC) to provide reflex functions that are somewhat autonomous from the CNS (Rao and Gershon, 2018). Enteroendocrine cells secrete a wide array of neurotransmitters and signaling molecules to stimulate enteric neuronal activity in response to the changing GI environment. ICCs are the resident intestinal pacemaker cells and modulate smooth muscle contraction independent of neuronal input. The regulation of the peristaltic reflex by the ENS is triggered by the activation of intrinsic primary afferent neurons (IPANs) by GI luminal distension or neurotransmitters such as serotonin, which are released by the enteroendocrine cells. IPANs, project their axons into the intestinal mucosa, transmitting their signals to ascending and descending interneurons. Ascending interneurons synapse with cholinergic $\left(\mathrm{ChAT}^{+}\right)$excitatory motor neurons eliciting contraction of the intestinal smooth muscle proximal to the site of IPAN activation by acetylcholine (Ach) release. Descending interneurons synapse with inhibitory motor neurons and induce smooth muscle relaxation distal to the site of IPAN stimulation by release of multiple neurotransmitters including: nitric oxide and vasoactive intestinal peptide (VIP). The combination of contraction and relaxation of the intestinal smooth muscles is the basis for the peristaltic reflex in the GI tract. Glial cells are also present in the ENS, and like the astrocytes in the CNS, protect the endothelial barriers in the GI while also maintaining optimal conditions for neuronal function. However, the cellular complexity of the ENS makes it challenging to model in vitro.

\section{The Evolving Landscape of Gastrointestinal and ENS Organoids}

Waardenburg syndrome and Hirschsprung's disease are severe enteric neuropathies that are often fatal; thus, highlighting the essential role of ENS in regulating intestinal tissue activity (Brosens et al., 2016). Unfortunately, studying the molecular underpinnings of these neuropathies has been nearly impossible due to a dearth of ENS models with the spatial complexity of the human intestine. Recently, at least two strategies have been developed to derive human intestinal organoids (HIOs) that incorporate ENS like tissue (Schlieve et al., 2017; Workman et al., 2017). A combination of TGF- $\beta$, WNT3A, and FGF4 signaling was used to induce embryonic stem cells (ESCs) or iPSCs to 
generate mid and hindgut tissues. These HIOs had similar epithelial cell and mesenchymal distribution as normal human intestinal tissue, but lacked ENS cells (McCracken et al., 2011; Spence et al., 2011). Vagal neural crest progenitor cells (NCCs) derived from iPSCs by using retinoic acid (RA) were subsequently incorporated into HIOs (Fattahi et al., 2016; Workman et al., 2017). Immunohistochemical staining of HIOs aggregated with NCCs (termed HIOs + ENS organoids) revealed that enteric neurons and glia populated the smooth muscle layers of the HIOs, like the enteric ganglia do in vivo in the GI tract. However, they did not contain all the enteric neural cell types as only IPANs, ChAT ${ }^{+}$excitatory neurons, dopaminergic neurons, and some types of inhibitory neurons were observed. Notably HIOs + ENS lacked glia as well as enteric inhibitory neurons, which actively express nitric oxide synthase (NOS) and function in smooth muscle relaxation. The functionality of in vitro derived organoids in terms of their capacity to mature and integrate in vivo has been tested in "chimeric" models transplanting human stem cell derived tissue into live animals. HIOs + ENS engrafted into live mouse kidneys had increased NOSexpressing inhibitory neurons, reduced $\mathrm{ChAT}^{+}$neurons, and diminished numbers of enteric neuronal cell bodies compared to actual human intestine. These results suggest that aggregation of NCCs with HIOs do not contain all of the intrinsic cues that are essential for the timely appearance of ENS excitatory and inhibitory neurons. Alternatively, the kidney environment might not have been as supportive for ENS development as would have been engraftment into the GI. Despite the alterations in neuronal cell type composition, neurons within the HIOs + ENS were functional as shown by $\mathrm{Ca}^{2+}$ efflux measurement. HIOs + ENS neurons mediated sustained intestinal smooth muscle contraction and relaxation independent of ICCs. An important discovery using the HIOs + ENS model is that the ENS promotes cellular proliferation and differentiation of intestinal cells. HIOs + ENS, but not HIOs alone, lead to increased cell proliferation in the intestinal crypt, which correlated with increased expression of genes regulating proliferation and intestinal cell development.

Schlieve et al. (2017) reported the development of a more "in vivo" like ENS containing organoids enriched in multiple enteric neuronal and glial cells. ENS neurons were derived from iPSCs cultured in RA, inhibitors of BMP and TGF- $\beta$ signaling, and activators of GSK signaling. A key difference with the HIOS + ENS method, was that NCCs and HIOs were seeded onto polyglycolic acid scaffolds, and were implanted into the omentum of irradiated mice for in vivo maturation. The omentum is a fold of the peritoneum connecting the stomach with other abdominal tissues. Therefore, this could provide a more permissive environment to the development of more in vivo like ENS. This organoid model referred to as ENCC-HIO-TESI (enteric neural crest cells - human intestinal organoid - tissue engineered small intestine) contained epithelial and mesenchymal cells associated with mature human intestinal tissue. ENCC-HIO-TESI also contained excitatory $\mathrm{ChAT}^{+}$neurons, serotonin ${ }^{+}$IPANs, ascending and descending interneurons, inhibitory $\mathrm{NOS}^{+}$neurons and enteric glial cells. Enteric glia (SOX10/GFAP ${ }^{+}$and SOX10/S100 $\beta^{+}$) was also found throughout the ENCC-HIO-TESI mesenchyme. This was in stark contrast to the HIOs + ENS (Workman et al., 2017), where excitatory $\mathrm{ChAT}^{+}$and inhibitory $\mathrm{NOS}^{+}$neurons where not present simultaneously and lacked enteric glia. While HIOs + ENS had an apparent lack of neuroepithelial connections, confocal microscopy analysis of ENCC-HIO-TESI showed that axons from enteric neurons projected into the cell bodies of enteroendocrine cells (Schlieve et al., 2017). Similar to HIOs + ENS, neurons in ENCC-HIO-TESI were also shown to regulate contraction and relaxation of intestinal muscles. Therefore, ENCC-HIO-TESI restored connections between enteric neural and non-neural cells and could more faithfully recapitulate the mutual dependence of each cell type in ensuring proper intestine function.

A future challenge in the study of the GI and ENS in vitro will be the development of in vitro culturing conditions that mimic the omentum environment. The combination of NCC and HIOs derived from separate populations of stem cells demonstrates the success and potential of co-culturing organoids for modeling human tissues. The development of organoid cultures that contain multiple progenitor populations is also observed in the development of organoid cultures in the neuroendocrine axis.

\section{ORGANOID MODELING OF THE NEUROENDOCRINE AXIS}

\section{Pituitary Development in vivo}

The endocrine system refers to a collection of glands that secrete hormones to regulate various physiological processes, like metabolism, reproduction, and growth. The pituitary gland is often nicknamed the "master gland" because its hormones help regulate other endocrine glands, including the thyroid gland and adrenal glands. Mutations in genes that control pituitary development may result in hypopituitarism, or a deficiency in a single or multiple pituitary hormone cell types. On the other hand, pituitary adenomas can cause the secretion of excess hormones, leading to disorders such as gigantism, or Cushing's disease. Current treatment for pituitary dysfunction includes hormone replacement therapy. However, not all pituitary hormones have replacement therapy, some therapies are typically discontinued after puberty, and proper dosage is complicated and variable. For example, it is difficult to properly mimic the circadian or stress-induced change in hormone levels (Suga et al., 2016). Therefore, pituitary cell replacement therapies would greatly improve upon current hormone replacement treatments.

The pituitary gland is derived from two different ectodermal structures; namely the oral and neural ectoderm. Oral ectoderm will produce Rathke's pouch, the precursor for the pituitary anterior lobe. Neural ectoderm will give rise to the pituitary posterior lobe via an infundibulum of the ventral diencephalon. The patterning of the ventral diencephalon, which includes an organizing center expressing BMP4, FGF8, and FGF10, is important both for the formation of the posterior lobe itself, and for generating the pituitary progenitors in Rathke's pouch (Davis et al., 2013). Canonical WNT signaling in the ventral diencephalon promotes the expression of this pituitary organizing center, especially the expression of FGF8, 
which controls the proper size and shape of Rathke's pouch (Osmundsen et al., 2017).

After the formation of the pituitary gland, the endocrine system and nervous system continue to be intimately linked through hormone secretion. The hypothalamus, which develops from the ventral portion of the diencephalon serves to integrate sensory inputs, process them, and effect responses to regulate basic needs such as stress responses, energy and fluid balance, growth, and even emotional homeostasis. This is accomplished through the release of hormones from the axon terminals of the neuroendocrine neurons into the fenestrated portal blood capillaries of the median eminence and pituitary posterior lobe (Pearson and Placzek, 2013). The proximity of these axon terminals and portal vessels allows hypothalamic neurohormones and neurotransmitters to be released into the bloodstream for delivery to target cells. In the posterior lobe, pituicytes, which are astrocytic-like cells, can modulate the release of neurohormones (Wittkowski, 1998). In the median eminence, radial glial-like tanycytes are thought to support the bidirectional flow of components between the hypothalamus and circulatory systems (Wittkowski, 1998). Regulating peptides, including growth hormone-releasing hormone (GHRH), somatostatin (SST), dopamine (DA), thyroid-releasing hormone (TRH), and corticotropin-releasing hormone (CRH), can also be released and passed through the pituitary portal system to control the production and release of anterior pituitary hormones (Pearson and Placzek, 2013).

\section{Neuroendocrine Deficits in Neurodevelopmental Disorders}

Prader-Willi syndrome (PWS), a complex multisystem genetic disorder, is characterized by short stature, muscle hypotonia, hyperphagia, obesity, hypogonadism, behavioral problems, and developmental delay (Holm et al., 1993; Goldstone et al., 2008; Angulo et al., 2015). Children with PWS have impaired growth, most likely caused by a combination of growth hormone (GH)/insulin-like growth factor 1 (IGF-1) deficiency and a lack of pubertal growth spurt (Driscoll et al., 1993; Grugni et al., 2011; Bakker et al., 2017). Most PWS patients fall into the mildly intellectually disabled range, have multiple severe learning disabilities, and poor academic performance (Whittington et al., 2004). In addition, children with PWS are at risk for autism spectrum disorder (ASD), including pervasive social deficits (Zyga et al., 2015). To treat PWS, individuals are given GH therapy (Aycan and Bas, 2014). However, reports of sudden death have occurred in PWS patients on GH, and those undergoing treatment should exercise extreme caution (Van Vliet et al., 2004; Bakker et al., 2007). In addition to PWS, there have been multiple reports of other chromosomal abnormalities that bridge endocrine defects and neurodevelopmental disorders. For example, individuals with Tetrasomy $\mathrm{X}$, a rare aneuploidy seen in girls, have facial dysmorphism, premature ovarian insufficiency, intellectual disability, and according to some reports, skeletal abnormalities (Uppal et al., 2017). Additional, patients with Tetrasomy X developed early growth hormone deficiency and later developed partial secondary adrenal insufficiency and central hypothyroidism (Uppal et al., 2017). There has also been a report of a male subject with a maternally inherited deletion of approximately $5.8 \mathrm{Mb}$ at Xq21.1, who has shown developmental delay, dysmorphic facial features, cleft palate, intellectual disability, short stature, and hearing loss, which correlated with multiple pituitary hormone deficiency (Giordano et al., 2015). Another patient with Xq21.1 deletion was found to have severe growth retardation, moderate mental retardation, microcephaly, cleft palate, hearing loss, and secondary adrenal insufficiency due to isolated ACTH deficiency (Kajantie et al., 2004). Taken together, a better understanding of the interactions between the endocrine system and the nervous system may allow for better diagnosis or treatment of these disorders (Figure 1).

\section{Recapitulating Pituitary and Hypothalamus Organogenesis in vitro}

Since 3D organoids can be used to model embryonic development, they are ideal for studying the development of the pituitary gland and hypothalamic tissue. Watanabe et al. (2005) and Eiraku et al. (2008) established a three-dimensional suspension culture method for ES cells called "serum-free culture of embryoid body-like aggregates with quick re-aggregation (SFEBq)." This culture method utilizes aggregates of ES cells in culturing conditions suitable for differentiation into ectodermal derivatives. Under these conditions, the ES cells also spontaneously form highly ordered structures and display self-organization (Sasai et al., 2012). Using SFEBq cultures, Wataya et al. (2008) was able to induce hypothalamic neurons from mouse ES cells. The hypothalamic neurons were most efficiently produced in growth factor-free, chemically defined medium (gfCDM) and in the presence of Sonic Hedgehog (SHH), which lead to the differentiation of rostral-ventral hypothalamic precursors and neurons (Suga et al., 2016). Removing exogenous growth factors, instead of adding inductive signals, played a key role in rostral hypothalamic specification and suggests that the default fate of mouse ES cells is rostral hypothalamus (Wataya et al., 2008).

In addition to establishing hypothalamic tissue from mouse ES cells using the SFEBq cultures, researchers were also able to generate pituitary hormone cell types. By increasing the size of the ES cell aggregate Suga et al. (2011) established culture conditions that allowed oral ectoderm to co-exist with hypothalamic tissue. Ochiai et al. (2015) also showed that differentiation into non-neural ectoderm was facilitated by low concentrations of exogenous BMP4 treatment. Since $\mathrm{SHH}$ is essential for providing midline identity in the ventral diencephalon (Zhu et al., 2007), Suga et al. (2011) added the smoothened agonist (SAG), which stimulates the SHH signaling pathway. With this addition, ES cell aggregates formed vesicles that expressed LHX3, a marker for the pituitary progenitors in Rathke's pouch. These pituitary progenitors were able to differentiate into all of the anterior lobe hormone cell types, with adrenocorticotropic hormone (ACTH) secreting corticotropes being the most efficiently produced (Suga et al., 2016). Suga et al. (2011) then transplanted these ACTH secreting pituitary organoids into the kidney capsule of 
a hypophysectomized mouse. After 1 week, blood ACTH levels were slightly, but significantly increased, and corticosterone, which is released from the adrenal gland upon ACTH stimulation, was also significantly increased. This suggests that the pituitary organoid was able to respond to endogenous signals and restore the hypothalamic-pituitary-adrenal axis, despite its ectopic location in the kidney capsule (Suga et al., 2016). These results demonstrate the feasibility of cell replacement therapy to treat hypopituitarism.

Ozone et al. (2016) were able to recapitulate pituitary development in vitro in human ES cells using the SFEBq method. They found that the anterior pituitary self-formed after these large aggregates generated both hypothalamic and oral ectoderm. Interestingly, a single aggregate could contain multiple LHX3+ pouches, while only one pouch normally develops in the embryo. Unfortunately, there did not seem to be a high success rate for the development of these pouches in vitro, with only $4.0 \pm 0.4$ vesicles per eight aggregates, suggesting that the organoid culture conditions can be improved to more efficiently generate pituitary progenitors. The most common cells types produced in the hESCs pituitary organoids are corticotrophs and somatotrophs (Ozone et al., 2016). Gonadotropes and thyrotropes are not efficiently produced in these cultures, suggesting that additional work is needed to generate these cell types in the quantities needed for cell replacement therapy.

The key interaction in the large aggregates in SFEBq culture is likely the interaction between neural ectoderm and surface ectoderm, which can generate a placode, similar to the adenohypophyseal placode that generates Rathke's pouch. Zimmer et al. (2016) used human pluripotent stem cells (hPSCs) to generate pituitary hormone cell types in $2 \mathrm{D}$ culture by first inducing cranial placode progenitors from the hPSCs and then driving the differentiation of pituitary progenitors and specific hormone cell types by manipulating key signaling pathways in culture. Their data indicates that pituitary cell fate can be induced independent of the self-organization seen in the SFEBq 3D culture (Zimmer et al., 2016). ACTH secreting cells generated in this manner were transplanted subcutaneously into hypophysectomized rats and displayed evidence of survival and hormone release for up to 7 weeks after transplantation. This process of transplantation of individual pituitary cells is a promising route for the restoration of the hypothalamic-pituitary axis function in patients with a deficit (Rizzoti et al., 2016). However, patients with combined pituitary hormone deficiency will either require cell replacement with multiple cells types generated separately or the transplantation of a pituitary organoid containing multiple anterior pituitary hormone cell types. The pituitary gland is a highly organized 3D structure where each cell type is part of an interconnected network that responds to hypothalamic releasing hormones in an organized fashion (Le Tisser et al., 2012). While pituitary hormone cell types can be generated and studied in $2 \mathrm{D}$ culture, the ultimate goal for cell replacement therapy should be the generation of pituitary organoids that mimic the $3 \mathrm{D}$ structure of the pituitary gland.

\section{CHALLENGES AND FUTURE PERSPECTIVES}

Formation of forebrain, retinal tissue, choroid plexus and hindbrain were original observed by Lancaster et al. (2013) in stem cell derived "mini-brains" that were generated in the absence of exogenous patterning signals (Muratore et al., 2014). While exciting, one drawback of this system is that it is highly variable. Even among organoids cultured simultaneously under the same conditions in different vessels there is heterogeneity in terms of the cell type diversity (Quadrato et al., 2017). Development of brain-region specific organoids by addition of different morphogenetic proteins that provide specific patterning cues has increased the reproducibility of the system (Pasca, 2018b). This approach allows us to interrogate brain-region specific questions, but it limits us in terms of the study of neuronal connectivity. To address this issue, the integration of individually generated dorsal and ventral cortical brain regions was able to generate inhibitory interneurons that recapitulated their in vivo tangential migration (Birey et al., 2017) and the assembly of rudimentary neural circuits. This is a promising start, but a major challenge is generating organoids that display the complexity of mature human neural circuits. Part of this challenge is being met by transplantation experiments in mice in which human brain organoid grafts form functional neuronal networks with their host (Mansour et al., 2018).

As organoids grow in size and complexity, another major challenge is to provide oxygenation, nutrients, and structural integration of the vasculature to the organoids. Current methodologies have allowed researchers to grow brain organoids up to 510 days (Sloan et al., 2017, 2018) in the absence of a vascular system. However, the vascular niche is essential for proper brain development and function (Paredes et al., 2018), and efforts are being made to develop culturing conditions that incorporate a vascular system. Transplantation of human cerebral organoids into the murine brain showed the presence of blood vessels in the grafts (Mansour et al., 2018). Similarly, another report showed incorporation of endothelial cells into brain organoids in vitro, which were only shown to mature into blood vessels after transplantation into a live animal. iPSC-derived cerebral organoids were co-cultured for up to 3 to 5 weeks in vitro with endothelial cells from the same donor and transplanted at day 54 and analyzed after 2 weeks (Pham et al., 2018). The formation of mature blood vessels only after transplant suggests that co-culturing of brain organoids with endothelial cells alone is not enough to allow the maturation of the vasculature in vitro. Future directions might incorporate bioengineering approaches like 3D printing of blood vessels or "organ in a chip" type of technology (Lin et al., 2019) to overcome the challenge of vascularization of brain organoids in a complete in vitro system.

With respect to the neuro-immune axis one major challenge will be to model how neuroinflammation might affect fetal development. Growing evidence suggests a role for maternal 
inflammation during fetal development as a contributing factor to the complex etiology of neuropsychiatric disorders like autism and schizophrenia (Labouesse et al., 2015; Di Marco et al., 2016). Currently, animal models and epidemiological studies provide the majority of the evidence that suggests that maternal inflammation is correlated with neuropsychiatric disorders. To directly address this hypothesis in human tissue, co-culture systems that incorporate microglia and astrocytes with region specific brain organoids could be expanded to incorporate different brain regions. This "assembloyd" system could be used to test the cell autonomous effect of disease specific mutations in the formation of neural networks in vitro. Alternatively, the impact of different immune signaling molecules could also be assessed in co-culture systems of microglia and brain specific organoids, in self directed cerebral organoid systems that contain microglia or in "assembloyds."

With respect to the Gut-brain axis the recent key discovery that a subset of ENS enteroendocrine cells can directly synapse with cranial nerve axon terminals (Kaelberer et al., 2018) opens up the possibility that GI environmental cues (i.e., microbiota) could directly communicate with the CNS. Kaelberer et al. (2018) examined this circuit in vivo using transsynaptic spread of a GFP labeled rabies virus followed by electrophysiological measurements in response to glucose uptake. This circuit was recreated in vitro using a co-culture system of enteroendocrine cells and nodose vagal neurons (Kaelberer et al., 2018). Future studies that incorporate patient iPSC-derived GI and ENS organoid models with vagal nerve neurons could provide additional mechanistic insights into the

\section{REFERENCES}

Abreu, C. M., Gama, L., Krasemann, S., Chesnut, M., Odwin-Dacosta, S., Hogberg, H. T., et al. (2018). Microglia increase inflammatory responses in ipsc-derived human brainspheres. Front. Microbiol. 9:2766. doi: 10.3389/fmicb.2018.02766

Ahn, S., Kim, T. G., Kim, K. S., and Chung, S. (2016). Differentiation of human pluripotent stem cells into medial ganglionic eminence vs. caudal ganglionic eminence cells. Methods 101, 103-112. doi: 10.1016/j.ymeth.2015.09.009

Allen, N. J., and Lyons, D. A. (2018). Glia as architects of central nervous system formation and function. Science 362, 181-185. doi: 10.1126/science.aat0473

Alliot, F., Godin, I., and Pessac, B. (1999). Microglia derive from progenitors, originating from the yolk sac, and which proliferate in the brain. Brain Res. Dev. Brain Res. 117, 145-152. doi: 10.1016/s0165-3806(99)00113-3

Amin, N. D., and Pasca, S. P. (2018). Building models of brain disorders with threedimensional organoids. Neuron 100, 389-405. doi: 10.1016/j.neuron.2018. 10.007

Angulo, M. A., Butler, M. G., and Cataletto, M. E. (2015). Prader-Willi syndrome: a review of clinical, genetic, and endocrine findings. J. Endocrinol. Invest. 38, 1249-1263. doi: 10.1007/s40618-015-0312-9

Antoni, D., Burckel, H., Josset, E., and Noel, G. (2015). Three-dimensional cell culture: a breakthrough in vivo. Int. J. Mol. Sci. 16, 5517-5527. doi: 10.3390/ ijms 16035517

Asai, H., Ikezu, S., Tsunoda, S., Medalla, M., Luebke, J., Haydar, T., et al. (2015). Depletion of microglia and inhibition of exosome synthesis halt tau propagation. Nat. Neurosci. 18, 1584-1593. doi: 10.1038/nn.4132

Aycan, Z., and Bas, V. N. (2014). Prader-Willi syndrome and growth hormone deficiency. J. Clin. Res. Pediatr. Endocrinol. 6, 62-67. doi: 10.4274/Jcrpe.1228

Bae, B. I., Jayaraman, D., and Walsh, C. A. (2015). Genetic changes shaping the human brain. Dev. Cell 32, 423-434. doi: 10.1016/j.devcel.2015.01.035

Bahn, S., Mimmack, M., Ryan, M., Caldwell, M. A., Jauniaux, E., Starkey, M., et al. (2002). Neuronal target genes of the neuron-restrictive silencer factor in gut-brain connection in disorders such as Parkinson's disease, which has a known GI involvement.

Finally, with respect to the neuroendocrine axis, the assembly of multiple components this system could interrogate mechanisms underlying neural interactions with the hypothalamic-pituitary-adrenal gland axis, which has been previously associated to individuals at high risk of developing psychosis. While at the moment there are organoid models of adrenal glands, one could envision that being able to develop the hypothalamic-pituitary-adrenal gland axis in a dish could provide mechanistic insight on how corticosteroids could modulate neural circuits in the hypothalamus.

\section{AUTHOR CONTRIBUTIONS}

SBL, EC, and AO conceived and developed the manuscript. SBL, $\mathrm{EC}, \mathrm{AO}$, and $\mathrm{SD}$ wrote and edited the manuscript.

\section{FUNDING}

Center of Biomedical Excellence Dietary Supplements and Inflammation-NIGMS P20GM103641 and SC INBRE NIGMS P20GM103499 Pilot Award supported SBL. Research reported in this publication was supported in part by the SC EPSCoR/IDeA Program under award number 18-SR04 to SBL. The views, perspective, and content do not necessarily represent the official views of the SC EPSCoR/IDeA Program.

neurospheres derived from fetuses with down's syndrome: a gene expression study. Lancet 359, 310-315. doi: 10.1016/s0140-6736(02)07497-4

Bakker, B., Maneatis, T., and Lippe, B. (2007). Sudden death in Prader-Willi syndrome: brief review of five additional cases. concerning the article by eiholzer, u., et al.: deaths in children with prader-willi syndrome. a contribution to the debate about the safety of growth hormone treatment in children with PWS. Horm Res. 67, 203-204. doi: 10.1159/000097928

Bakker, N. E., Lindberg, A., Heissler, J., Wollmann, H. A., Camacho-Hubner, C., Hokken-Koelega, A. C., et al. (2017). Growth hormone treatment in children with prader-willi syndrome: three years of longitudinal data in prepubertal children and adult height data from the KIGS database. J. Clin. Endocrinol. Metab. 102, 1702-1711. doi: 10.1210/jc.2016-2962

Banks, W. A. (2015). The blood-brain barrier in neuroimmunology: tales of separation and assimilation. Brain Behav. Immun. 44, 1-8. doi: 10.1016/j.bbi. 2014.08.007

Banks, W. A., Niehoff, M. L., Ponzio, N. M., Erickson, M. A., and Zalcman, S. S. (2012). Pharmacokinetics and modeling of immune cell trafficking: quantifying differential influences of target tissues versus lymphocytes in SJL and lipopolysaccharide-treated mice. J. Neuroinflammation 9:231. doi: 10.1186/ 1742-2094-9-231

Bergmann, S., Lawler, S. E., Qu, Y., Fadzen, C. M., Wolfe, J. M., Regan, M. S., et al. (2018). Blood-brain-barrier organoids for investigating the permeability of CNS therapeutics. Nat. Protoc. 13, 2827-2843. doi: 10.1038/s41596-018-00 66-x

Bershteyn, M., Nowakowski, T. J., Pollen, A. A., Di Lullo, E., Nene, A., WynshawBoris, A., et al. (2017). Human iPSC-derived cerebral organoids model cellular features of lissencephaly and reveal prolonged mitosis of outer radial glia. Cell Stem Cell 20, 435-449e4. doi: 10.1016/j.stem.2016.12.007

Bialas, A. R., and Stevens, B. (2013). TGF-beta signaling regulates neuronal C1q expression and developmental synaptic refinement. Nat. Neurosci. 16, 1773-1782. doi: 10.1038/nn.3560 
Birey, F., Andersen, J., Makinson, C. D., Islam, S., Wei, W., Huber, N., et al. (2017). Assembly of functionally integrated human forebrain spheroids. Nature 545, 54-59. doi: 10.1038/nature22330

Brightman, M. W., and Reese, T. S. (1969). Junctions between intimately apposed cell membranes in the vertebrate brain. J. Cell Biol. 40, 648-677. doi: 10.1083/ jcb.40.3.648

Brosens, E., Burns, A. J., Brooks, A. S., Matera, I., Borrego, S., Ceccherini, I., et al. (2016). Genetics of enteric neuropathies. Dev. Biol. 417, 198-208. doi: 10.1016/j.ydbio.2016.07.008

Brown, J., Quadrato, G., and Arlotta, P. (2018). Studying the brain in a dish: 3d cell culture models of human brain development and disease. Curr. Top. Dev. Biol. 129, 99-122. doi: 10.1016/bs.ctdb.2018.03.002

Bruce-Keller, A. J., Salbaum, J. M., and Berthoud, H. R. (2018). Harnessing gut microbes for mental health: getting from here to there. Biol. Psychiatry 83, 214-223. doi: 10.1016/j.biopsych.2017.08.014

Campisi, M., Shin, Y., Osaki, T., Hajal, C., Chiono, V., Kamm, R. D., et al. (2018). 3D self-organized microvascular model of the human blood-brain barrier with endothelial cells, pericytes and astrocytes. Biomaterials 180, 117-129. doi: 10 . 1016/j.biomaterials.2018.07.014

Careaga, M., Murai, T., and Bauman, M. D. (2017). Maternal immune activation and autism spectrum disorder: from rodents to nonhuman and human primates. Biol. Psychiatry 8, 391-401. doi: 10.1016/j.biopsych.2016.10.020

Castillo, E., Leon, J., Mazzei, G., Abolhassani, N., Haruyama, N., Saito, T., et al. (2017). Comparative profiling of cortical gene expression in Alzheimer's disease patients and mouse models demonstrates a link between amyloidosis and neuroinflammation. Sci. Rep. 7:17762. doi: 10.1038/s41598-017-17999-3

Chen, H. I., Song, H., and Ming, G. L. (2019). Applications of human brain organoids to clinical problems. Dev. Dyn. 248, 53-64. doi: 10.1002/dvdy.24662

Cho, C. F., Wolfe, J. M., Fadzen, C. M., Calligaris, D., Hornburg, K., Chiocca, E. A., et al. (2017). Blood-brain-barrier spheroids as an in vitro screening platform for brain-penetrating agents. Nat. Commun. 8:15623. doi: 10.1038/ncomms1 5623

Choi, S. H., Kim, Y. H., Hebisch, M., Sliwinski, C., Lee, S., D’Avanzo, C., et al. (2014). A three-dimensional human neural cell culture model of Alzheimer's disease. Nature 515, 274-278. doi: 10.1038/nature13800

Cvetkovic, C., Basu, N., and Krencik, R. (2018). Synaptic microcircuit modeling with $3 \mathrm{~d}$ cocultures of astrocytes and neurons from human pluripotent stem cells. J. Vis. Exp. 138:e58034. doi: 10.3791/58034

Dalton, N., Chandler, S., Turner, C., Charman, T., Pickles, A., Loucas, T., et al. (2014). Gut permeability in autism spectrum disorders. Autism Res. 7, 305-313. doi: 10.1002/aur.1350

Darville, H., Poulet, A., Rodet-Amsellem, F., Chatrousse, L., Pernelle, J., Boissart, C., et al. (2016). Human pluripotent stem cell-derived cortical neurons for high throughput medication screening in autism: a proof of concept study in shank3 haploinsufficiency syndrome. EBioMedicine 9, 293-305. doi: 10.1016/j.ebiom. 2016.05.032

Davalos, D., Grutzendler, J., Yang, G., Kim, J. V., Zuo, Y., Jung, S., et al. (2005). ATP mediates rapid microglial response to local brain injury in vivo. Nat. Neurosci. 8, 752-758. doi: 10.1038/nn1472

Davis, S. W., Ellsworth, B. S., Perez Millan, M. I., Gergics, P., Schade, V., Foyouzi, N., et al. (2013). Pituitary gland development and disease: from stem cell to hormone production. Curr. Top. Dev. Biol. 106, 1-47. doi: 10.1016/B978-0-12416021-7.00001-8

Dawkins, E., and Small, D. H. (2014). Insights into the physiological function of the beta-amyloid precursor protein: beyond Alzheimer's disease. J. Neurochem. 129, 756-769. doi: 10.1111/jnc.12675

DeFelipe, J. (2015). The anatomical problem posed by brain complexity and size: a potential solution. Front. Neuroanat. 9:104. doi: 10.3389/fnana.2015.00104

Del Pino Rico, B., and Marin, O. (2018). Neural circuit dysfunction in mouse models of neurodevelopmental disorders. Curr. Opin. Neurobiol. 48, 174-182. doi: 10.1016/j.conb.2017.12.013

Di Marco, B., Bonaccorso, C. M., Aloisi, E., D’Antoni, S., and Catania, M. V. (2016). Neuro-Inflammatory mechanisms in developmental disorders associated with intellectual disability and autism spectrum disorder: a neuro- immune perspective. CNS Neurol. Disord. Drug Targets 15, 448-463. doi: 10.2174/ 1871527315666160321105039

Doe, C. Q. (2017). Temporal patterning in the drosophila CNS. Annu. Rev. Cell Dev. Biol. 33, 219-240. doi: 10.1146/annurev-cellbio-111315-125210
Driscoll, D. J., Miller, J. L., Schwartz, S., and Cassidy, S. B. (1993). "Prader-Willi syndrome," in GeneReviews $\$$, eds M. P. Adam, H. H. Ardinger, R. A. Pagon, S. E. Wallace, J. H. Bean, K. Stephens, (Seattle, WA: University of Washington, Seattle).

Eiraku, M., Watanabe, K., Matsuo-Takasaki, M., Kawada, M., Yonemura, S., Matsumura, M., et al. (2008). Self-organized formation of polarized cortical tissues from ESCs and its active manipulation by extrinsic signals. Cell Stem Cell 3, 519-532. doi: 10.1016/j.stem.2008.09.002

Estes, M. L., and McAllister, A. K. (2016). Maternal immune activation: implications for neuropsychiatric disorders. Science 353, 772-777. doi: 10.1126/ science.aag 3194

Farahany, N. A., Greely, H. T., Hyman, S., Koch, C., Grady, C., Pasca, S. P., et al. (2018). The ethics of experimenting with human brain tissue. Nature 556, 429-432. doi: 10.1038/d41586-018-04813-x

Fattahi, F., Steinbeck, J. A., Kriks, S., Tchieu, J., Zimmer, B., Kishinevsky, S., et al. (2016). Deriving human ENS lineages for cell therapy and drug discovery in Hirschsprung disease. Nature 531, 105-109. doi: 10.1038/nature16951

Felten, D. L. (1993). Direct innervation of lymphoid organs: substrate for neurotransmitter signaling of cells of the immune system. Neuropsychobiology 28, 110-112. doi: 10.1159/000119011

Felten, D. L., Felten, S. Y., Bellinger, D. L., and Madden, K. S. (1993). Fundamental aspects of neural-immune signaling. Psychother. Psychosom. 60, 46-56. doi: 10.1159/000288679

Fung, T. C., Olson, C. A., and Hsiao, E. Y. (2017). Interactions between the microbiota, immune and nervous systems in health and disease. Nat. Neurosci. 20, 145-155. doi: 10.1038/nn.4476

Garcez, P. P., Loiola, E. C., Madeiro da Costa, R., Higa, L. M., Trindade, P., Delvecchio, R., et al. (2016). Zika virus impairs growth in human neurospheres and brain organoids. Science 352, 816-818. doi: 10.1126/science.aaf6116

Ginhoux, F., Greter, M., Leboeuf, M., Nandi, S., See, P., Gokhan, S., et al. (2010). Fate mapping analysis reveals that adult microglia derive from primitive macrophages. Science 330, 841-845. doi: 10.1126/science.119 4637

Giordano, M., Gertosio, C., Pagani, S., Meazza, C., Fusco, I., Bozzola, E., et al. (2015). A 5.8 Mb interstitial deletion on chromosome Xq21.1 in a boy with intellectual disability, cleft palate, hearing impairment and combined growth hormone deficiency. BMC Med. Genet. 16:74. doi: 10.1186/s12881-0150220-z

Goldstone, A. P., Holland, A. J., Hauffa, B. P., Hokken-Koelega, A. C., Tauber, M., and Speakers Contributors at the Second Expert Meeting of the Comprehensive Care of Patients with PWS. (2008). Recommendations for the diagnosis and management of prader-Willi syndrome. J. Clin. Endocrinol. Metab. 93, 4183-4197. doi: 10.1210/jc.2008-0649

Gonzalez, C., Armijo, E., Bravo-Alegria, J., Becerra-Calixto, A., Mays, C. E., and Soto, C. (2018). Modeling amyloid beta and tau pathology in human cerebral organoids. Mol. Psychiatry. 23, 2363-2374. doi: 10.1038/s41380-018-0229-8

Grugni, G., Crino, A., Pagani, S., Meazza, C., Buzi, F., De Toni, T., et al. (2011). Growth hormone secretory pattern in non-obese children and adolescents with Prader-Willi syndrome. J. Pediatr. Endocrinol. Metab. 24, 477-481.

Gurdon, J. B. (1960). The developmental capacity of nuclei taken from differentiating endoderm cells of Xenopus laevis. J. Embryol. Exp. Morphol. 8, 505-526.

Gurdon, J. B., Elsdale, T. R., and Fischberg, M. (1958). Sexually mature individuals of Xenopus laevis from the transplantation of single somatic nuclei. Nature 182, 64-65. doi: 10.1038/182064a0

Hashimoto, T., Serrano-Pozo, A., Hori, Y., Adams, K. W., Takeda, S., Banerji, A. O., et al. (2012). Apolipoprotein E, especially apolipoprotein E4, increases the oligomerization of amyloid beta peptide. J. Neurosci. 32, 15181-15192. doi: 10.1523/JNEUROSCI.1542-12.2012

Hebert, J. M., and Fishell, G. (2008). The genetics of early telencephalon patterning: some assembly required. Nat. Rev. Neurosci. 9, 678-685. doi: 10.1038/nrn2463

Heide, M., Huttner, W. B., and Mora-Bermudez, F. (2018). Brain organoids as models to study human neocortex development and evolution. Curr. Opin. Cell Biol. 55, 8-16. doi: 10.1016/j.ceb.2018.06.006

Hoffman, G. E., Hartley, B. J., Flaherty, E., Ladran, I., Gochman, P., Ruderfer, D. M., et al. (2017). Transcriptional signatures of schizophrenia in hiPSCderived NPCs and neurons are concordant with post-mortem adult brains. Nat. Commun. 8:2225. doi: 10.1038/s41467-017-02330-5 
Holm, V. A., Cassidy, S. B., Butler, M. G., Hanchett, J. M., Greenswag, L. R., Whitman, B. Y., et al. (1993). Prader-Willi syndrome: consensus diagnostic criteria. Pediatrics 91, 398-402.

Homan, K. A., Gupta, N., Kroll, K. T., Kolesky, D. B., Skylar-Scott, M., Miyoshi, T., et al. (2019). Flow-enhanced vascularization and maturation of kidney organoids in vitro. Nat. Methods 16, 255-262. doi: 10.1038/s41592-019-0325-y

Hook, V., Brennand, K. J., Kim, Y., Toneff, T., Funkelstein, L., Lee, K. C., et al. (2014). Human iPSC neurons display activity-dependent neurotransmitter secretion: aberrant catecholamine levels in schizophrenia neurons. Stem Cell Rep. 3, 531-538. doi: 10.1016/j.stemcr.2014.08.001

Hu, B. Y., Du, Z. W., Li, X. J., Ayala, M., and Zhang, S. C. (2009). Human oligodendrocytes from embryonic stem cells: conserved $\mathrm{SHH}$ signaling networks and divergent FGF effects. Development 136, 1443-1452. doi: 10.1242/ dev.029447

Huang, Y. A., Zhou, B., Wernig, M., and Sudhof, T. C. (2017). ApoE2, ApoE3, and ApoE4 differentially stimulate APP transcription and abeta secretion. Cell 168, 427-441e21. doi: 10.1016/j.cell.2016.12.044

Israel, M. A., Yuan, S. H., Bardy, C., Reyna, S. M., Mu, Y., Herrera, C., et al. (2012). Probing sporadic and familial Alzheimer's disease using induced pluripotent stem cells. Nature 482, 216-220. doi: 10.1038/nature10821

Jabaudon, D., and Lancaster, M. (2018). Exploring landscapes of brain morphogenesis with organoids. Development 145:dev172049. doi: 10.1242/dev. 172049

Jhou, J. F., and Tai, H. C. (2017). The study of postmortem human synaptosomes for understanding alzheimer's disease and other neurological disorders: a review. Neurol. Ther. 6, 57-68. doi: 10.1007/s40120-017-0070-Z

Jo, J., Xiao, Y., Sun, A. X., Cukuroglu, E., Tran, H. D., Goke, J., et al. (2016). Midbrain-like organoids from human pluripotent stem cells contain functional dopaminergic and neuromelanin-producing neurons. Cell Stem Cell 19, 248-257. doi: 10.1016/j.stem.2016.07.005

Kaelberer, M. M., Buchanan, K. L., Klein, M. E., Barth, B. B., Montoya, M. M., Shen, $\mathrm{X}$., et al. (2018). A gut-brain neural circuit for nutrient sensory transduction. Science 361:eaat5236. doi: 10.1126/science.aat5236

Kajantie, E., Otonkoski, T., Kivirikko, S., and Somer, M. (2004). A syndrome with multiple malformations, mental retardation, and ACTH deficiency. Am. J. Med. Genet. A 126A, 313-318. doi: 10.1002/ajmg.a.20604

Kelava, I., and Lancaster, M. A. (2016). Dishing out mini-brains: current progress and future prospects in brain organoid research. Dev. Biol. 420, 199-209. doi: 10.1016/j.ydbio.2016.06.037

Kiba, T. (2006). Relationships between the autonomic nervous system, humoral factors and immune functions in the intestine. Digestion 74, 215-227. doi: 10.1159/000100512

Kikuti, M., Cardoso, C. W., Prates, A. P. B., Paploski, I. A. D., Kitron, U., Reis, M. G., et al. (2018). Congenital brain abnormalities during a Zika virus epidemic in Salvador, Brazil, April 2015 to July 2016. Euro. Surveill. 23:1700757. doi: 10.2807/1560-7917.ES.2018.23.45.1700757

Kim, T. G., Yao, R., Monnell, T., Cho, J. H., Vasudevan, A., Koh, A., et al. (2014). Efficient specification of interneurons from human pluripotent stem cells by dorsoventral and rostrocaudal modulation. Stem Cells 32, 1789-1804. doi: 10.1002/stem.1704

Kim, Y. H., Choi, S. H., D’Avanzo, C., Hebisch, M., Sliwinski, C., Bylykbashi, E., et al. (2015). A 3D human neural cell culture system for modeling Alzheimer's disease. Nat. Protoc. 10, 985-1006. doi: 10.1038/nprot.2015.065

Krencik, R., Seo, K., van Asperen, J. V., Basu, N., Cvetkovic, C., Barlas, S., et al. (2017). Systematic three-dimensional coculture rapidly recapitulates interactions between human neurons and astrocytes. Stem Cell Rep. 9, 1745-1753. doi: 10.1016/j.stemcr.2017.10.026

Kretzschmar, H. (2009). Brain banking: opportunities, challenges and meaning for the future. Nat. Rev. Neurosci. 10, 70-78. doi: 10.1038/nrn2535

Labouesse, M. A., Langhans, W., and Meyer, U. (2015). Long-term pathological consequences of prenatal infection: beyond brain disorders. Am. J. Physiol. Regul. Integr. Comp. Physiol. 309, R1-R12. doi: 10.1152/ajpregu.00087.2015

Lancaster, M. A., and Knoblich, J. A. (2014a). Generation of cerebral organoids from human pluripotent stem cells. Nat. Protoc. 9, 2329-2340. doi: 10.1038/ nprot.2014.158

Lancaster, M. A., and Knoblich, J. A. (2014b). Organogenesis in a dish: modeling development and disease using organoid technologies. Science 345:1247125. doi: $10.1126 /$ science. 1247125
Lancaster, M. A., Renner, M., Martin, C. A., Wenzel, D., Bicknell, L. S., Hurles, M. E., et al. (2013). Cerebral organoids model human brain development and microcephaly. Nature 501, 373-379. doi: 10.1038/nature12517

Lauschke, K., Frederiksen, L., and Hall, V. J. (2017). Paving the way toward complex blood-brain barrier models using pluripotent stem cells. Stem Cells Dev. 26, 857-874. doi: 10.1089/scd.2017.0003

Le, Tissier PR, Hodson, D. J., Lafont, C., Fontanaud, P., Schaeffer, M., and Mollard, P. (2012). Anterior pituitary cell networks. Front. Neuroendocrinol. 33:252-266. doi: 10.1016/j.yfrne.2012.08.002

Lehtinen, M. K., and Walsh, C. A. (2011). Neurogenesis at the brain-cerebrospinal fluid interface. Annu. Rev. Cell Dev. Biol. 27, 653-679. doi: 10.1146/annurevcellbio-092910-154026

Li, Y., Muffat, J., Omer, A., Bosch, I., Lancaster, M. A., Sur, M., et al. (2017). Induction of expansion and folding in human cerebral organoids. Cell Stem Cell 20, 385-396e3. doi: 10.1016/j.stem.2016.11.017

Lin, D. S. Y., Guo, F., and Zhang, B. (2019). Modeling organ-specific vasculature with organ-on-a-chip devices. Nanotechnology 30:024002. doi: 10.1088/13616528/aae7de

Lin, Y. T., Seo, J., Gao, F., Feldman, H. M., Wen, H. L., Penney, J., et al. (2018). APOE4 causes widespread molecular and cellular alterations associated with alzheimer's disease phenotypes in human ipsc-derived brain cell types. Neuron 98, 1141-1154e7. doi: 10.1016/j.neuron.2018.05.008

Lippmann, E. S., Al-Ahmad, A., Azarin, S. M., Palecek, S. P., and Shusta, E. V. (2014). A retinoic acid-enhanced, multicellular human blood-brain barrier model derived from stem cell sources. Sci. Rep. 4:4160. doi: 10.1038/srep0 4160

Lippmann, E. S., Al-Ahmad, A., Palecek, S. P., and Shusta, E. V. (2013). Modeling the blood-brain barrier using stem cell sources. Fluids Barriers CNS 10:2. doi: 10.1186/2045-8118-10-2

Liu, S. J., Nowakowski, T. J., Pollen, A. A., Lui, J. H., Horlbeck, M. A., Attenello, F. J., et al. (2016). Single-cell analysis of long non-coding RNAs in the developing human neocortex. Genome Biol. 17:67. doi: 10.1186/s13059-0160932-1

Lopez, M. F., Krastins, B., and Ning, M. (2014). The role of apolipoprotein E in neurodegeneration and cardiovascular disease. Expert Rev. Proteomics 11, 371-381. doi: 10.1586/14789450.2014.901892

Lu, J., Delli-Bovi, L. C., Hecht, J., Folkerth, R., and Sheen, V. L. (2011). Generation of neural stem cells from discarded human fetal cortical tissue. J. Vis. Exp. 51:2681. doi: 10.3791/2681

Lui, J. H., Hansen, D. V., and Kriegstein, A. R. (2011). Development and evolution of the human neocortex. Cell 146, 18-36. doi: 10.1016/j.cell.2011.06.030

Mack, C. L., Vanderlugt-Castaneda, C. L., Neville, K. L., and Miller, S. D. (2003). Microglia are activated to become competent antigen presenting and effector cells in the inflammatory environment of the Theiler's virus model of multiple sclerosis. J. Neuroimmunol. 144, 68-79. doi: 10.1016/j.jneuroim.2003. 08.032

Mansour, A. A., Goncalves, J. T., Bloyd, C. W., Li, H., Fernandes, S., Quang, D., et al. (2018). An in vivo model of functional and vascularized human brain organoids. Nat. Biotechnol. 36, 432-441. doi: 10.1038/nbt.4127

Marchetto, M. C., Muotri, A. R., Mu, Y., Smith, A. M., Cezar, G. G., and Gage, F. H. (2008). Non-cell-autonomous effect of human SOD1 G37R astrocytes on motor neurons derived from human embryonic stem cells. Cell Stem Cell 3, 649-657. doi: 10.1016/j.stem.2008.10.001

Mariani, J., Coppola, G., Zhang, P., Abyzov, A., Provini, L., Tomasini, L., et al. (2015). FOXG1-dependent dysregulation of GABA/glutamate neuron differentiation in autism spectrum disorders. Cell 162, 375-390. doi: 10.1016/ j.cell.2015.06.034

Maroof, A. M., Keros, S., Tyson, J. A., Ying, S. W., Ganat, Y. M., Merkle, F. T., et al. (2013). Directed differentiation and functional maturation of cortical interneurons from human embryonic stem cells. Cell Stem Cell 12, 559-572. doi: 10.1016/j.stem.2013.04.008

Marton, R. M., Miura, Y., Sloan, S. A., Li, Q., Revah, O., Levy, R. J., et al. (2019). Differentiation and maturation of oligodendrocytes in human threedimensional neural cultures. Nat. Neurosci. 22, 484-491. doi: 10.1038/s41593018-0316-9

Marton, R. M., and Pasca, S. P. (2016). Neural differentiation in the third dimension: generating a human midbrain. Cell Stem Cell 19, 145-146. doi: 10.1016/j.stem.2016.07.017 
McCracken, K. W., Howell, J. C., Wells, J. M., and Spence, J. R. (2011). Generating human intestinal tissue from pluripotent stem cells in vitro. Nat. Protoc. 6, 1920-1928. doi: 10.1038/nprot.2011.410

McGeer, P. L., and McGeer, E. G. (2013). The amyloid cascade-inflammatory hypothesis of Alzheimer disease: implications for therapy. Acta Neuropathol. 126, 479-497. doi: 10.1007/s00401-013-1177-7

Mlakar, J., Korva, M., Tul, N., Popovic, M., Poljsak-Prijatelj, M., Mraz, J., et al. (2016). Zika virus associated with microcephaly. N. Engl. J. Med. 374, 951-958. doi: 10.1056/NEJMoa1600651

Moore, S., Evans, L. D., Andersson, T., Portelius, E., Smith, J., Dias, T. B., et al. (2015). APP metabolism regulates tau proteostasis in human cerebral cortex neurons. Cell Rep. 11, 689-696. doi: 10.1016/j.celrep.2015.03.068

Muffat, J., Li, Y., and Jaenisch, R. (2016a). CNS disease models with human pluripotent stem cells in the CRISPR age. Curr. Opin. Cell Biol. 43, 96-103. doi: 10.1016/j.ceb.2016.10.001

Muffat, J., Li, Y., Yuan, B., Mitalipova, M., Omer, A., Corcoran, S., et al. (2016b). Efficient derivation of microglia-like cells from human pluripotent stem cells. Nat. Med. 22, 1358-1367. doi: 10.1038/nm.4189

Muffat, J., Li, Y., Omer, A., Durbin, A., Bosch, I., Bakiasi, G., et al. (2018). Human induced pluripotent stem cell-derived glial cells and neural progenitors display divergent responses to Zika and dengue infections. Proc. Natl. Acad. Sci. U.S.A. 115, 7117-7122. doi: 10.1073/pnas.1719266115

Muratore, C. R., Rice, H. C., Srikanth, P., Callahan, D. G., Shin, T., Benjamin, L. N., et al. (2014). The familial Alzheimer's disease APPV717I mutation alters APP processing and Tau expression in iPSC-derived neurons. Hum. Mol. Genet. 23, 3523-3536. doi: 10.1093/hmg/ddu064

Muratore, C. R., Zhou, C., Liao, M., Fernandez, M. A., Taylor, W. M., Lagomarsino, V. N., et al. (2017). Cell-type dependent Alzheimer's disease phenotypes: probing the biology of selective neuronal vulnerability. Stem Cell Rep. 9, 1868-1884. doi: 10.1016/j.stemcr.2017.10.015

Namba, Y., Tomonaga, M., Kawasaki, H., Otomo, E., and Ikeda, K. (1991). Apolipoprotein E immunoreactivity in cerebral amyloid deposits and neurofibrillary tangles in Alzheimer's disease and kuru plaque amyloid in Creutzfeldt-Jakob disease. Brain Res. 541, 163-166. doi: 10.1016/0006-8993(91) 91092-f

Nardone, S., and Elliott, E. (2016). The interaction between the immune system and epigenetics in the etiology of autism spectrum disorders. Front. Neurosci. 10:329. doi: 10.3389/fnins.2016.00329

Nicolas-Avila, J. A., Hidalgo, A., and Ballesteros, I. (2018). Specialized functions of resident macrophages in brain and heart. J. Leukoc. Biol. 104, 743-756. doi: 10.1002/JLB.6MR0118-041R

Nowakowski, T. J., Bhaduri, A., Pollen, A. A., Alvarado, B., Mostajo-Radji, M. A., Di Lullo, E., et al. (2017). Spatiotemporal gene expression trajectories reveal developmental hierarchies of the human cortex. Science 358, 1318-1323. doi: 10.1126/science.aap 8809

Nowakowski, T. J., Rani, N., Golkaram, M., Zhou, H. R., Alvarado, B., Huch, K., et al. (2018). Regulation of cell-type-specific transcriptomes by microRNA networks during human brain development. Nat. Neurosci. 21, 1784-1792. doi: 10.1038/s41593-018-0265-3

Nzou, G., Wicks, R. T., Wicks, E. E., Seale, S. A., Sane, C. H., Chen, A., et al. (2018). Human cortex spheroid with a functional blood brain barrier for highthroughput neurotoxicity screening and disease modeling. Sci. Rep. 8:7413. doi: 10.1038/s41598-018-25603-5

Ochiai, H., Suga, H., Yamada, T., Sakakibara, M., Kasai, T., Ozone, C., et al. (2015). BMP4 and FGF strongly induce differentiation of mouse ES cells into oral ectoderm. Stem Cell Res. 15, 290-298. doi: 10.1016/j.scr.2015.06.011

Ormel, P. R., Vieira de Sa, R., van Bodegraven, E. J., Karst, H., Harschnitz, O., Sneeboer, M. A. M., et al. (2018). Microglia innately develop within cerebral organoids. Nat. Commun. 9:4167. doi: 10.1038/s41467-018-06684-2

Osmundsen, A. M., Keisler, J. L., Taketo, M. M., and Davis, S. W. (2017). Canonical WNT signaling regulates the pituitary organizer and pituitary gland formation. Endocrinology 158, 3339-3353. doi: 10.1210/en.2017-00581

Ozone, C., Suga, H., Eiraku, M., Kadoshima, T., Yonemura, S., Takata, N., et al. (2016). Functional anterior pituitary generated in self-organizing culture of human embryonic stem cells. Nat. Commun. 7:10351. doi: 10.1038/ ncomms 10351

Pamies, D., Barreras, P., Block, K., Makri, G., Kumar, A., Wiersma, D., et al. (2017). A human brain microphysiological system derived from induced pluripotent stem cells to study neurological diseases and toxicity. ALTEX 34, 362-376. doi: 10.14573/altex.1609122

Paolicelli, R. C., Bolasco, G., Pagani, F., Maggi, L., Scianni, M., Panzanelli, P., et al. (2011). Synaptic pruning by microglia is necessary for normal brain development. Science 333, 1456-1458. doi: 10.1126/science.1202529

Paredes, I., Himmels, P., and Ruiz de Almodovar, C. (2018). Neurovascular Communication during CNS Development. Dev. Cell 45, 10-32. doi: 10.1016/j. devcel.2018.01.023

Pasca, A. M., Sloan, S. A., Clarke, L. E., Tian, Y., Makinson, C. D., Huber, N., et al. (2015). Functional cortical neurons and astrocytes from human pluripotent stem cells in 3D culture. Nat. Methods 12, 671-678. doi: 10.1038/nmeth.3415

Pasca, S. P. (2018a). Building three-dimensional human brain organoids. Nat. Neurosci. doi: 10.1038/s41593-018-0107-3 [Epub ahead of print].

Pasca, S. P. (2018b). The rise of three-dimensional human brain cultures. Nature 553, 437-445. doi: 10.1038/nature25032

Pearson, C. A., and Placzek, M. (2013). Development of the medial hypothalamus: forming a functional hypothalamic-neurohypophyseal interface. Curr. Top. Dev. Biol. 106, 49-88. doi: 10.1016/B978-0-12-416021-7.00002-X

Pescosolido, M. F., Stein, D. M., Schmidt, M., El Achkar, C. M., Sabbagh, M., Rogg, J. M., et al. (2014). Genetic and phenotypic diversity of NHE6 mutations in Christianson syndrome. Ann. Neurol. 76, 581-593. doi: 10.1002/ana.24225

Pham, M. T., Pollock, K. M., Rose, M. D., Cary, W. A., Stewart, H. R., Zhou, P., et al. (2018). Generation of human vascularized brain organoids. Neuroreport 29, 588-593. doi: 10.1097/WNR.0000000000001014

Pinho-Ribeiro, F. A., Verri, W. A., and Chiu, I. M. (2017). Nociceptor Sensory Neuron-Immune Interactions in Pain and Inflammation. Trends Immunol. 38, 5-19. doi: 10.1016/j.it.2016.10.001

Pollen, A. A., Nowakowski, T. J., Chen, J., Retallack, H., Sandoval-Espinosa, C., Nicholas, C. R., et al. (2015). Molecular identity of human outer radial glia during cortical development. Cell 163, 55-67. doi: 10.1016/j.cell.2015.09.004

Pollen, A. A., Nowakowski, T. J., Shuga, J., Wang, X., Leyrat, A. A., Lui, J. H., et al. (2014). Low-coverage single-cell mRNA sequencing reveals cellular heterogeneity and activated signaling pathways in developing cerebral cortex. Nat. Biotechnol. 32, 1053-1058. doi: 10.1038/nbt.2967

Qian, X., Jacob, F., Song, M. M., Nguyen, H. N., Song, H., and Ming, G. L. (2018). Generation of human brain region-specific organoids using a miniaturized spinning bioreactor. Nat. Protoc. 13, 565-580. doi: 10.1038/nprot.2017.152

Qian, X., Nguyen, H. N., Jacob, F., Song, H., and Ming, G. L. (2017). Using brain organoids to understand Zika virus-induced microcephaly. Development 144, 952-957. doi: 10.1242/dev.140707

Qian, X., Nguyen, H. N., Song, M. M., Hadiono, C., Ogden, S. C., Hammack, C., et al. (2016). Brain-region-specific organoids using mini-bioreactors for modeling zikv exposure. Cell 165, 1238-1254. doi: 10.1016/j.cell.2016. 04.032

Quadrato, G., and Arlotta, P. (2017). Present and future of modeling human brain development in 3D organoids. Curr. Opin. Cell Biol. 49, 47-52. doi: 10.1016/j. ceb.2017.11.010

Quadrato, G., Brown, J., and Arlotta, P. (2016). The promises and challenges of human brain organoids as models of neuropsychiatric disease. Nat. Med. 22, 1220-1228. doi: 10.1038/nm.4214

Quadrato, G., Nguyen, T., Macosko, E. Z., Sherwood, J. L., Min Yang, S., Berger, D. R., et al. (2017). Cell diversity and network dynamics in photosensitive human brain organoids. Nature 545, 48-53. doi: 10.1038/nature 22047

Raja, W. K., Mungenast, A. E., Lin, Y. T., Ko, T., Abdurrob, F., Seo, J., et al. (2016). Self-organizing $3 \mathrm{~d}$ human neural tissue derived from induced pluripotent stem cells recapitulate alzheimer's disease phenotypes. PLoS One 11:e0161969. doi: 10.1371/journal.pone.0161969

Rana, P., Luerman, G., Hess, D., Rubitski, E., Adkins, K., and Somps, C. (2017). Utilization of iPSC-derived human neurons for high-throughput drug-induced peripheral neuropathy screening. Toxicol. In Vitro 45, 111-118. doi: 10.1016/j. tiv.2017.08.014

Rao, M., and Gershon, M. D. (2018). Enteric nervous system development: what could possibly go wrong? Nat. Rev. Neurosci. 19, 552-565. doi: 10.1038/s41583018-0041-0

Reese, T. S., and Karnovsky, M. J. (1967). Fine structural localization of a bloodbrain barrier to exogenous peroxidase. J. Cell Biol. 34, 207-217. doi: 10.1083/ jcb.34.1.207 
Regen, F., Hellmann-Regen, J., Costantini, E., and Reale, M. (2017). Neuroinflammation and Alzheimer's disease: implications for microglial activation. Curr. Alzheimer Res. 14, 1140-1148. doi: 10.2174/ 1567205014666170203141717

Renner, M., Lancaster, M. A., Bian, S., Choi, H., Ku, T., Peer, A., et al. (2017). Selforganized developmental patterning and differentiation in cerebral organoids. EMBO J. 36, 1316-1329. doi: 10.15252/embj.201694700

Rizzoti, K., Pires, C., and Lovell-Badge, R. (2016). "Perspective on stem cells in developmental biology, with special reference neuroendocrine systems," in Stem Cells in Neuroendocrinology, eds D. Pfaff and Y. Christen (Berlin: Springer), 135-156. doi: 10.1007/978-3-319-41603-8_11

Rothhammer, V., and Quintana, F. J. (2015). Role of astrocytes and microglia in central nervous system inflammation. Semin. Immunopathol. 37, 575-576. doi: $10.1007 / \mathrm{s} 00281-015-0521-5$

Salick, M. R., Wells, M. F., Eggan, K., and Kaykas, A. (2017). Modelling zika virus infection of the developing human brain in vitro using stem cell derived cerebral organoids. J. Vis. Exp. 127:56404. doi: 10.3791/56404

Sanchez-Mejias, E., Navarro, V., Jimenez, S., Sanchez-Mico, M., Sanchez-Varo, R., Nunez-Diaz, C., et al. (2016). Soluble phospho-tau from Alzheimer's disease hippocampus drives microglial degeneration. Acta Neuropathol. 132, 897-916. doi: 10.1007/s00401-016-1630-5

Santos, R., Vadodaria, K. C., Jaeger, B. N., Mei, A., Lefcochilos-Fogelquist, S., Mendes, A. P. D., et al. (2017). Differentiation of inflammation-responsive astrocytes from glial progenitors generated from human induced pluripotent stem cells. Stem Cell Rep. 8, 1757-1769. doi: 10.1016/j.stemcr.2017.05.011

Sasai, Y., Eiraku, M., and Suga, H. (2012). In vitro organogenesis in three dimensions: self-organising stem cells. Development 139, 4111-4121. doi: 10. 1242/dev.079590

Saurat, N. G., Livesey, F. J., and Moore, S. (2016). Cortical differentiation of human pluripotent cells for in vitro modeling of Alzheimer's disease. Methods Mol. Biol. 1303, 267-278. doi: 10.1007/978-1-4939-2627-5_16

Schafer, D. P., Lehrman, E. K., Kautzman, A. G., Koyama, R., Mardinly, A. R., Yamasaki, R., et al. (2012). Microglia sculpt postnatal neural circuits in an activity and complement-dependent manner. Neuron 74, 691-705. doi: 10. 1016/j.neuron.2012.03.026

Schlieve, C. R., Fowler, K. L., Thornton, M., Huang, S., Hajjali, I., Hou, X., et al. (2017). Neural crest cell implantation restores enteric nervous system function and alters the gastrointestinal transcriptome in human tissue-engineered small intestine. Stem Cell Rep. 9, 883-896. doi: 10.1016/j.stemcr.2017.07.017

Seo, J., Kritskiy, O., Watson, L. A., Barker, S. J., Dey, D., Raja, W. K., et al. (2017). Inhibition of p25/Cdk5 attenuates tauopathy in mouse and ipsc models of frontotemporal dementia. J. Neurosci. 37, 9917-9924. doi: 10.1523/ JNEUROSCI.0621-17.2017

Setia, H., and Muotri, A. R. (2019). Brain organoids as a model system for human neurodevelopment and disease. Semin. Cell Dev. Bio. [Epub ahead of print],

Shaltouki, A., Peng, J., Liu, Q., Rao, M. S., and Zeng, X. (2013). Efficient generation of astrocytes from human pluripotent stem cells in defined conditions. Stem Cells 31, 941-952. doi: 10.1002/stem.1334

Sheen, V. L., Ferland, R. J., Harney, M., Hill, R. S., Neal, J., Banham, A. H., et al. (2006). Impaired proliferation and migration in human Miller-Dieker neural precursors. Ann. Neurol. 60, 137-144. doi: 10.1002/ana.20843

Shi, Y., Kirwan, P., Smith, J., MacLean, G., Orkin, S. H., and Livesey, F. J. (2012a). A human stem cell model of early Alzheimer's disease pathology in Down syndrome. Sci. Transl. Med. 4:124ra29. doi: 10.1126/scitranslmed.3003771

Shi, Y., Kirwan, P., Smith, J., Robinson, H. P., and Livesey, F. J. (2012b). Human cerebral cortex development from pluripotent stem cells to functional excitatory synapses. Nat. Neurosci. 15:S1.

Shirai, Y. (1921). On the transplantation of the rat sarcoma in adult heterogeneous animals. Jap. Med. World 1, 14-15. doi: 10.1038/nm.4041

Shitamukai, A., Konno, D., and Matsuzaki, F. (2011). Oblique radial glial divisions in the developing mouse neocortex induce self-renewing progenitors outside the germinal zone that resemble primate outer subventricular zone progenitors. J. Neurosci. 31, 3683-3695. doi: 10.1523/JNEUROSCI.477310.2011

Sloan, S. A., Andersen, J., Pasca, A. M., Birey, F., and Pasca, S. P. (2018). Generation and assembly of human brain region-specific threedimensional cultures. Nat. Protoc. 13, 2062-2085. doi: 10.1038/s41596-018$0032-7$
Sloan, S. A., Darmanis, S., Huber, N., Khan, T. A., Birey, F., Caneda, C., et al. (2017). Human astrocyte maturation captured in $3 \mathrm{~d}$ cerebral cortical spheroids derived from pluripotent stem cells. Neuron 95:e6. doi: 10.1016/j.neuron.2017.07.035

Song, B. H., Yun, S. I., Woolley, M., and Lee, Y. M. (2017). Zika virus: history, epidemiology, transmission, and clinical presentation. J. Neuroimmunol. 308, 50-64. doi: 10.1016/j.jneuroim.2017.03.001

Song, L., Yuan, X., Jones, Z., Griffin, K., Zhou, Y., Ma, T., et al. (2019). Assembly of Human stem cell-derived cortical spheroids and vascular spheroids to model 3-d brain-like tissues. Sci. Rep. 9:5977. doi: 10.1038/s41598-019-42439-9

Spence, J. R., Mayhew, C. N., Rankin, S. A., Kuhar, M. F., Vallance, J. E., Tolle, K., et al. (2011). Directed differentiation of human pluripotent stem cells into intestinal tissue in vitro. Nature 470, 105-109. doi: 10.1038/nature09691

Strafela, P., Vizjak, A., Mraz, J., Mlakar, J., Pizem, J., Tul, N., et al. (2017). Zika virus-associated micrencephaly: a thorough description of neuropathologic findings in the fetal central nervous system. Arch. Pathol. Lab. Med. 141, 73-81. doi: 10.5858/arpa.2016-0341-SA

Su, A., Gandhy, R., Barlow, C., and Triadafilopoulos, G. (2017). A practical review of gastrointestinal manifestations in Parkinson's disease. Parkin. Relat. Disord. 39, 17-26. doi: 10.1016/j.parkreldis.2017.02.029

Suga, H., Kadoshima, T., Minaguchi, M., Ohgushi, M., Soen, M., Nakano, T., et al. (2011). Self-formation of functional adenohypophysis in three-dimensional culture. Nature 480, 57-62. doi: 10.1038/nature10637

Suga, H., Pfaff, D., and Christen, Y. (eds) (2016). "Recapitulating hypothalamus and pituitary development using embryonic stem/induced pluripotent," in Stem Cells in Neuroendocrinology, (Berlin: Springer), 35-50. doi: 10.1007/978-3-31941603-8_4

Sun, T., and Hevner, R. F. (2014). Growth and folding of the mammalian cerebral cortex: from molecules to malformations. Nat. Rev. Neurosci. 15, 217-232. doi: $10.1038 / \mathrm{nrn} 3707$

Swinnen, N., Smolders, S., Avila, A., Notelaers, K., Paesen, R., Ameloot, M., et al. (2013). Complex invasion pattern of the cerebral cortex bymicroglial cells during development of the mouse embryo. Glia 61, 150-163. doi: 10.1002/glia. 22421

Takahashi, K., Tanabe, K., Ohnuki, M., Narita, M., Ichisaka, T., Tomoda, K., et al. (2007). Induction of pluripotent stem cells from adult human fibroblasts by defined factors. Cell 131, 861-872. doi: 10.1016/j.cell.2007.11.019

Takahashi, K., and Yamanaka, S. (2006). Induction of pluripotent stem cells from mouse embryonic and adult fibroblast cultures by defined factors. Cell 126, 663-676. doi: 10.1016/j.cell.2006.07.024

Tang, H., Hammack, C., Ogden, S. C., Wen, Z., Qian, X., Li, Y., et al. (2016). Zika virus infects human cortical neural progenitors and attenuates their growth. Cell Stem Cell 18, 587-590. doi: 10.1016/j.stem.2016.02.016

Tremblay, M. E., Lowery, R. L., and Majewska, A. K. (2010). Microglial interactions with synapses are modulated by visual experience. PLoS Biol. 8:e1000527. doi: 10.1371/journal.pbio.1000527

Uppal, S., Jee, Y. H., Lightbourne, M., Han, J. C., and Stratakis, C. A. (2017). Combined pituitary hormone deficiency in a girl with 48. XXXX and Rathke's cleft cyst. Hormones 16, 92-98. doi: 10.14310/horm.2002.1723

Van Vliet, G., Deal, C. L., Crock, P. A., Robitaille, Y., and Oligny, L. L. (2004). Sudden death in growth hormone-treated children with Prader-Willi syndrome. J. Pediatr. 144, 129-131. doi: 10.1016/j.jpeds.2003.09.049

Vehmas, A. K., Kawas, C. H., Stewart, W. F., and Troncoso, J. C. (2003). Immune reactive cells in senile plaques and cognitive decline in Alzheimer's disease. Neurobiol. Aging 24, 321-331. doi: 10.1016/s0197-4580(02)00090-8

Wang, C., Ward, M. E., Chen, R., Liu, K., Tracy, T. E., Chen, X., et al. (2017). Scalable Production of iPSC-derived human neurons to identify tau-lowering compounds by high-content screening. Stem Cell Rep. 9, 1221-1233. doi: 10. 1016/j.stemcr.2017.08.019

Wang, P., Mokhtari, R., Pedrosa, E., Kirschenbaum, M., Bayrak, C., Zheng, D., et al. (2017). CRISPR/Cas9-mediated heterozygous knockout of the autism gene CHD8 and characterization of its transcriptional networks in cerebral organoids derived from iPS cells. Mol. Autism 8:11. doi: 10.1186/s13229-0170124-1

Watanabe, K., Kamiya, D., Nishiyama, A., Katayama, T., Nozaki, S., Kawasaki, H., et al. (2005). Directed differentiation of telencephalic precursors from embryonic stem cells. Nat. Neurosci. 8, 288-296.

Wataya, T., Ando, S., Muguruma, K., Ikeda, H., Watanabe, K., Eiraku, M., et al. (2008). Minimization of exogenous signals in ES cell culture induces rostral 
hypothalamic differentiation. Proc. Natl. Acad. Sci. U.S.A. 105, 11796-11801. doi: $10.1073 /$ pnas.0803078105

Weed, L. H. (1917). The development of the cerebrospinal fluid spaces in pig and in man. Contrib. Embryol. Carnegie Inst. 5, 1-116.

Wells, M. F., Salick, M. R., Wiskow, O., Ho, D. J., Worringer, K. A., Ihry, R. J., et al. (2016). Genetic Ablation of AXL Does Not Protect Human Neural Progenitor Cells and Cerebral Organoids from Zika Virus Infection. Cell Stem Cell 19, 703-708. doi: 10.1016/j.stem.2016.11.011

Whittington, J., Holland, A., Webb, T., Butler, J., Clarke, D., and Boer, H. (2004). Academic underachievement by people with Prader-Willi syndrome. J. Intellect. Disabil. Res. 48, 188-200. doi: 10.1111/j.1365-2788.2004.00473.x

Wislocki, G. B. (1891). Experimental studies on fetal absorption: I, the vitality stained fetus. Contrib. Embryol. Carnegie Inst. VI, 45-52.

Wittkowski, W. (1998). Tanycytes and pituicytes: morphological and functional aspects of neuroglial interaction. Microsc. Res. Tech. 41, 29-42. doi: $\quad$ 10.1002/(sici)1097-0029(19980401)41\%3A1\%3C29\%3A\%3Aaid-jemt4\% 3E3.0.co\%3B2-p

Workman, M. J., Mahe, M. M., Trisno, S., Poling, H. M., Watson, C. L., Sundaram, N., et al. (2017). Engineered human pluripotent-stem-cell-derived intestinal tissues with a functional enteric nervous system. Nat. Med. 23, 49-59. doi: 10.1038/nm.4233

Wu, Y., Dissing-Olesen, L., MacVicar, B. A., and Stevens, B. (2015). Microglia: dynamic mediators of synapse development and plasticity. Trends Immunol. 36, 605-613. doi: 10.1016/j.it.2015.08.008

Yoon, K. J., Ringeling, F. R., Vissers, C., Jacob, F., Pokrass, M., Jimenez-Cyrus, D., et al. (2017a). Temporal control of mammalian cortical neurogenesis by $\mathrm{m}(6) \mathrm{a}$ methylation. Cell 171, 877-889e17. doi: 10.1016/j.cell.2017.09.003

Yoon, K. J., Song, G., Qian, X., Pan, J., Xu, D., Rho, H. S., et al. (2017b). ZikaVirus-encoded NS2A disrupts mammalian cortical neurogenesis by degrading adherens junction proteins. Cell Stem Cell 21:e6. doi: 10.1016/j.stem.2017. 07.014
Yu, D. X., Di, F., Giorgio, P., Yao, J., Marchetto, M. C., Brennand, K., et al. (2014). Modeling hippocampal neurogenesis using human pluripotent stem cells. Stem Cell Rep. 2, 295-310. doi: 10.1016/j.stemcr.2014.01.009

Zenaro, E., Piacentino, G., and Constantin, G. (2017). The blood-brain barrier in Alzheimer's disease. Neurobiol. Dis. 107, 41-56. doi: 10.1016/j.nbd.2016.07.007

Zhu, G., Zhau, H. E., He, H., Zhang, L., Shehata, B., Wang, X., et al. (2007). Sonic and desert hedgehog signaling in human fetal prostate development. Prostate 67, 674-684. doi: 10.1002/pros.20563

Zila, I., Mokra, D., Kopincova, J., Kolomaznik, M., Javorka, M., and Calkovska, A. (2017). Vagal-immune interactions involved in cholinergic anti-inflammatory pathway. Physiol. Res. 66, S139-S145.

Zimmer, B., Piao, J., Ramnarine, K., Tomishima, M. J., Tabar, V., and Studer, L. (2016). Derivation of diverse hormone-releasing pituitary cells from human pluripotent stem cells. Stem Cell Rep. 6, 858-872. doi: 10.1016/j.stemcr.2016. 05.005

Zyga, O., Russ, S., Ievers-Landis, C. E., and Dimitropoulos, A. (2015). Assessment of pretend play in Prader-Willi syndrome: a direct comparison to autism spectrum disorder. J. Autism. Dev. Disord. 45, 975-987. doi: 10.1007/s10803014-2252-1

Conflict of Interest Statement: The authors declare that the research was conducted in the absence of any commercial or financial relationships that could be construed as a potential conflict of interest.

Copyright (c) 2019 Chukwurah, Osmundsen, Davis and Lizarraga. This is an openaccess article distributed under the terms of the Creative Commons Attribution License (CC BY). The use, distribution or reproduction in other forums is permitted, provided the original author(s) and the copyright owner(s) are credited and that the original publication in this journal is cited, in accordance with accepted academic practice. No use, distribution or reproduction is permitted which does not comply with these terms. 